Research Article

\title{
Sequential Measurement and Analysis of Large Underground Retaining Structures by Diaphragm Wall Anchor for the Spring Area
}

\author{
Jicheng Shu, ${ }^{1}$ Jianping Sun, ${ }^{2}$ Dingwen Zhang ${ }^{(D,},{ }^{1}$ and Huanwei Wei ${ }^{2}$ \\ ${ }^{1}$ Institute of Geotechnical Engineering, School of Transportation, Southeast University, 2 Sipailou, Nanjing 210096, China \\ ${ }^{2}$ School of Civil Engineering, Shandong Jianzhu University, Fengming Road 1000\#, Jinan 250014, China \\ Correspondence should be addressed to Dingwen Zhang; zhangdw@seu.edu.cn
}

Received 25 April 2019; Revised 28 June 2019; Accepted 16 July 2019; Published 11 November 2019

Academic Editor: Eric Lui

Copyright (c) 2019 Jicheng Shu et al. This is an open access article distributed under the Creative Commons Attribution License, which permits unrestricted use, distribution, and reproduction in any medium, provided the original work is properly cited.

The performance of a diaphragm wall-anchor structure in spring area in Jinan city, China, is studied. Based on field measured data, lateral wall deflections, lateral soil movements, horizontal displacement of the capping beam, the maximum lateral wall deflection, ground surface settlement, lateral earth pressures on diaphragm wall, internal force of diaphragm wall, axial anchoring forces, settlements of adjacent building, and pore-water pressure are investigated. The results indicate that the maximum deflections of the lateral wall are $0.07 \% \sim 0.18 \%$ of the excavation depth $\left(H_{\mathrm{e}}\right)$. The ground surface settlement influence zone extends beyond $2.5 H_{\mathrm{e}}$ from the pit for this project. The $\delta_{\mathrm{v}, \max }$ ranges from $0.67 \delta_{\mathrm{h}, \max }$ to $1.0 \delta_{\mathrm{h}, \max }$. The maximum lateral active earth pressures on diaphragm walls above the excavation bases range between $0.4 H_{\mathrm{e}}$ and $0.6 H_{\mathrm{e}}$. The axial anchoring forces of the top three layers of anchors change significantly during the excavation while the axial anchoring force of the fourth layer of anchor is constant. The deformation of surrounding building has three stages, including a uniform subsidence stage, an accelerated subsidence stage, and a stable subsidence stage.

\section{Introduction}

With the rapid development of underground space in urban areas, deep excavations have been increasing around the world. Meanwhile, the supporting structures and adjacent facilities security are a challenge due to deep excavations construction. Therefore, field monitoring of structure deformations and ground movements plays a vital role in excavation process [1-18]. Based on the reported field monitoring data, empirical and semiempirical methods have been identified as an appropriate approaches for the prediction of the excavation deformations [19-38]. These studies not only have put forward the cognitions of excavations deformations, but also are available to designers who would verify the numerical analysis for complex excavations. Figure 1 shows the typical displacement features of a braced deep excavation.
Spring city, Jinan, Shandong province is a famous city in China. Jinan city is located in the typical clay area in east China. There are four springs around this city, such as Baotu Spring, Pearl Spring, Black Tiger Spring, and Five Dragon Pool. Given the rapid development of the urban areas in Jinan, more and more deep excavations have been constructed over past years. However, little excavation monitoring information in Jinan can be found on the published reports and literatures, so that the design and construction of a deep excavation rely on local experience to a large extent. In this study, an excavation located in core area which is supported by diaphragm wall-anchor structure is investigated. Field monitoring of lateral deflections and vertical deformations of diaphragm wall, subsurface soil movement, soil pressure, pore-water pressure, ground settlement, axial force of anchor, groundwater table level, and settlement of adjacent building are reported, analyzed, and discussed. 


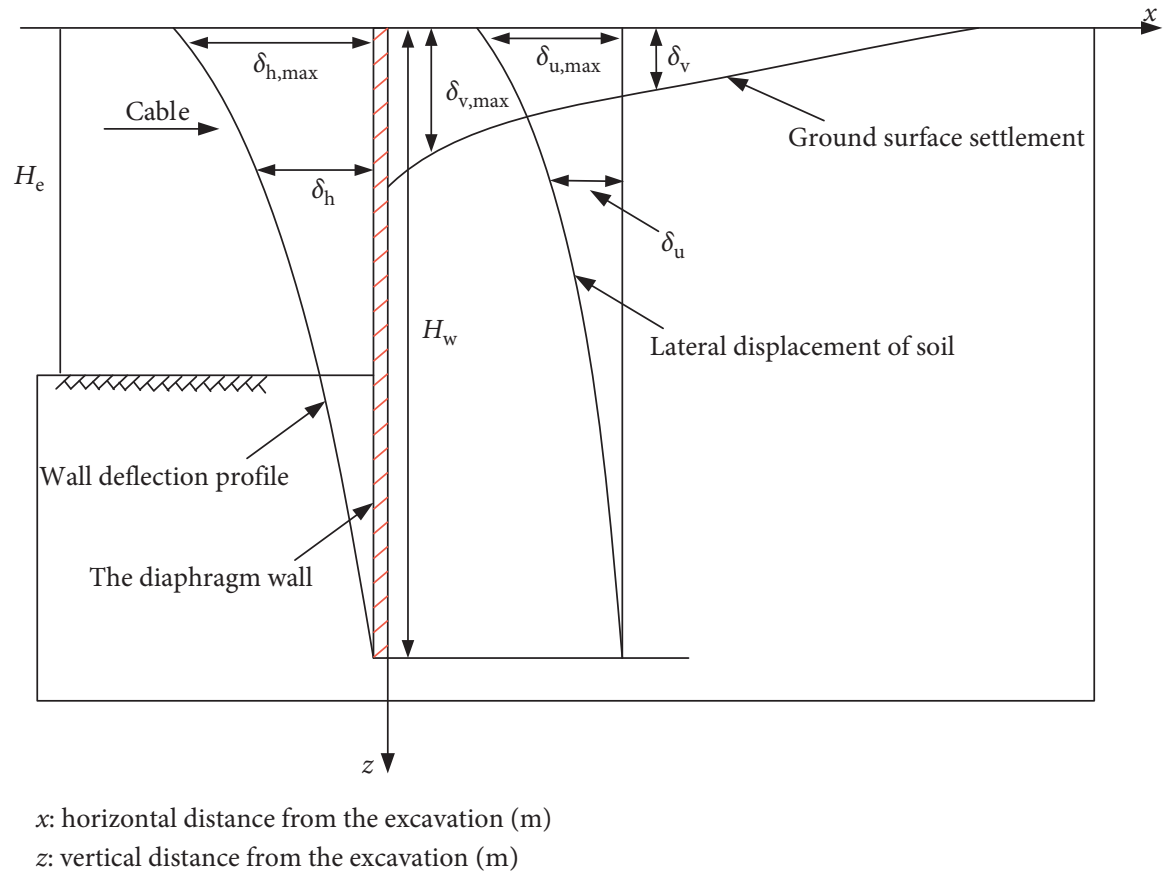

Figure 1: Sketch for the displacement of deep excavations.

\section{Site Conditions and Project Information}

2.1. Site Conditions. Jinan is located in the north of Taishan monoclinic hydrogeological area. Taishan mountain composed of ancient metamorphic rocks is the recharge area of surface water and groundwater. Paleozoic Cambrian and Ordovician carbonate strata overlying metamorphic rocks is consistent with the terrain, digging to the north of quaternary. A large number of Yanshan magmatite is distributed in the northern and eastern of the urban area. Yellow River strip carboniferous is above of Ordovician system in the western. This particular topography controls the region's aquifer and groundwater movement characteristics in this area. Jinan spring water originates from the southern mountain. The atmospheric precipitation flows along the limestone formations toward the north direction and encounters igneous rock beside the Yellow River. The igneous rock is impermeable, so that the confined water comes out to the ground surface and the spring is born. Figure 2 shows the geology and origination of springs. The investigated excavation is located in the west of spring core area, $260 \mathrm{~m}$ away from Five Dragon Pool in the northeast, $680 \mathrm{~m}$ away from Baotu Spring in the southeast, $1900 \mathrm{~m}$ away from Black Tiger Spring in the southeast, and $1250 \mathrm{~m}$ away from Pearl Spring in the northeast. There is a Unicom building that has 5 floors in the northeast corner of the excavation. The foundation of Unicom building is the strip foundation. Figure 3 shows the location relationship between the four springs and the field area. Figure 4 shows the support systems of typical section, and Figure 5 shows the connection node of the diaphragm walls and cables.

2.2. Geology and Soil Parameters. The site is thick clay soils comprising quaternary artificial fill and Holocene-
Pleistocene alluvial layer in this project. It is essential and necessary to assess the soil properties with the investigation of site geology. The investigation of soil conditions at the site had been carried out by a series of soil exploration programs. The strata concerned in this excavation site include eight layers with total depth up to $50 \mathrm{~m}$. The top upper layer is formed by artificial fill with a thickness of $2.22 \mathrm{~m}$ in general. Underlying is silty clay, with medium plasticity and strength. The average thickness of this layer is $4.4 \mathrm{~m}$. The third layer is tawny clay with a thickness of $0.8-3.5 \mathrm{~m}$, which is hard plastic and high tough. Below this stratum is brown clay with a thickness of 0.4-6.8 m, which was deposited in the medium pleistocene geological period. Beneath this layer is a $0.8-$ $7.9 \mathrm{~m}$ thick gravel layer. It is gray, saturated, poor uniformity, but the compactness is between medium dense and high dense. The sixth layer is residual soil with a thickness of $1.3-10 \mathrm{~m}$, which comes from Diorite rock. It is gray-green, lowly plastic. Underlying is a full weathered diorite with a thickness of $1.2-11.6 \mathrm{~m}$, which is gray, much broken, and lowly taken. The eighth layer is strongly weathered diorite with a thickness of $0.6-9 \mathrm{~m}$. The form of the diorite core is coarse granular or gravel granular. The last layer is medium weathered diorite. This layer is gray-green, hard, medium grain structure, which consists of feldspar and calcite crystal. The diorite core is much brittle and the rate of extract is $60-80 \%$. Average geotechnical parameters of the site layers are also included in Figure 6.

2.3. Construction Sequence. This excavation had seven sections (i.e., $\mathrm{AB}$ segment, $\mathrm{BC}$ segment, $\mathrm{CD}$ segment, $\mathrm{DE}$ segment, EF segment, FG segment, and GA segment), and the total length was $386 \mathrm{~m}$. A large area of excavation at the same time was strictly forbidden and the anchors or concrete 


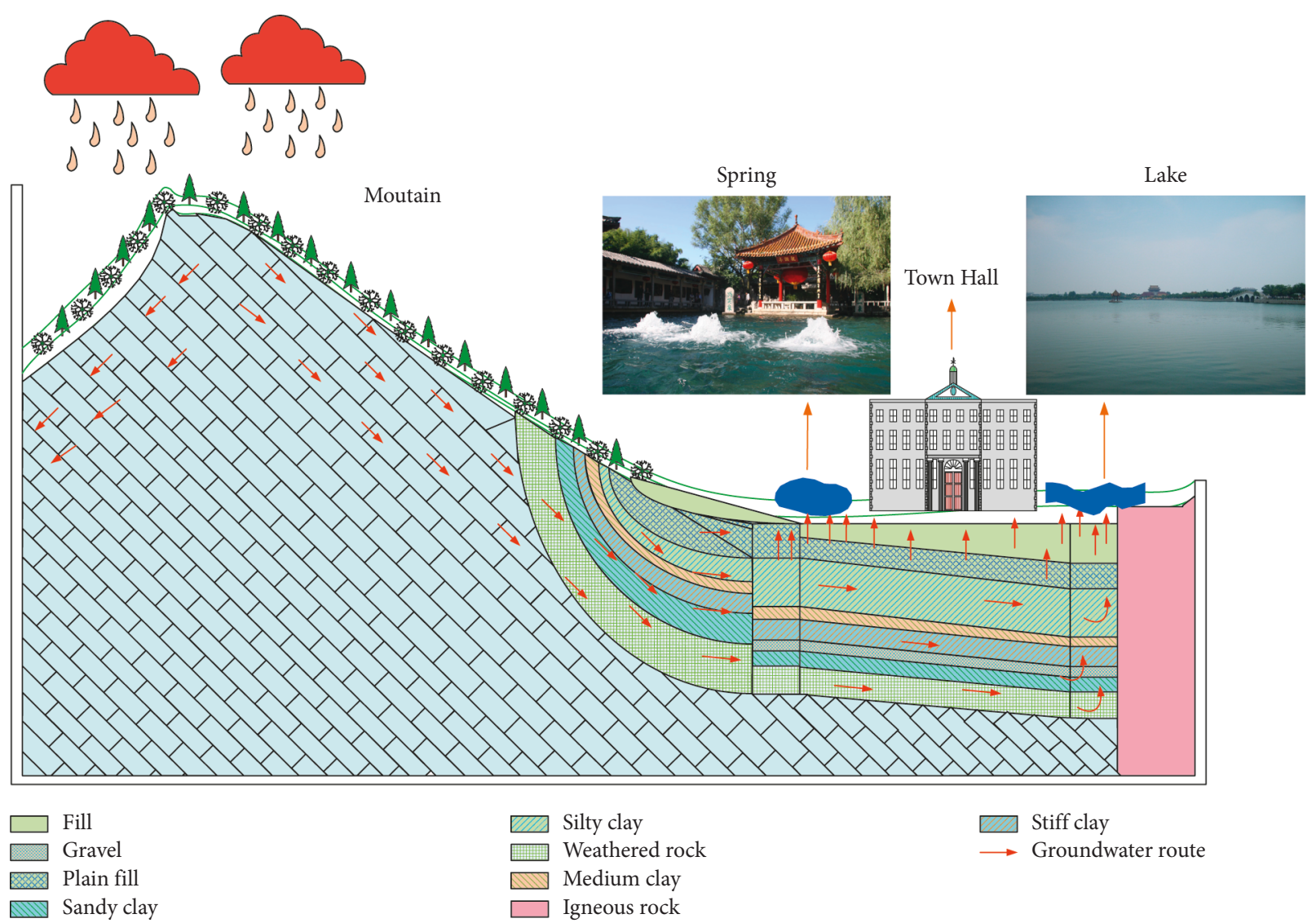

FIGURE 2: Geology and origination of springs.

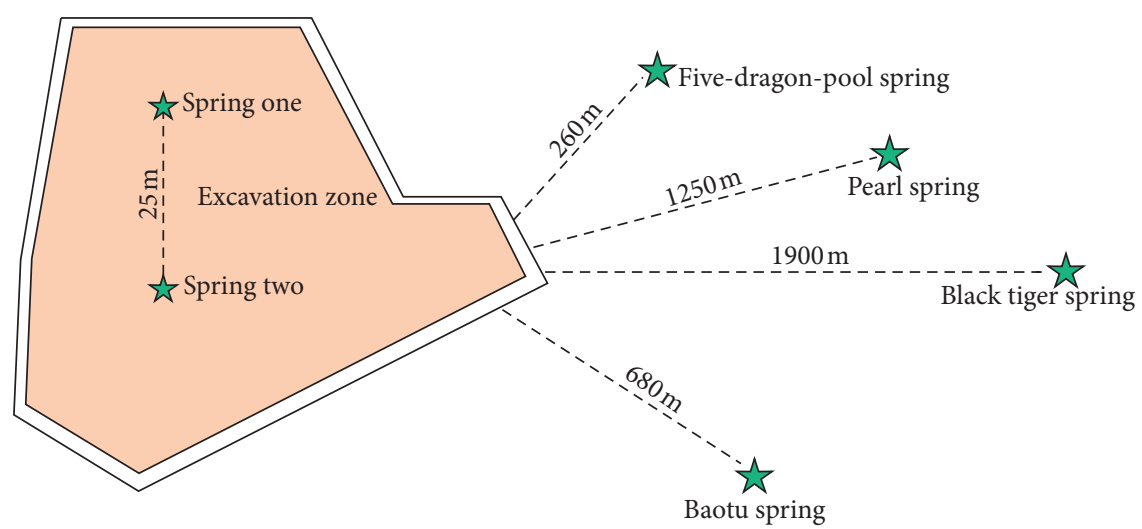

FIgURE 3: Location of excavation site (not to scale).

struts should be under construction in time after excavation to the basal level. Figure 4 presents the cross section of the $\mathrm{H}-\mathrm{H}$ shaft. The filed site started with constructing the $0.8 \mathrm{~m}-$ thick $\times 27.3 \mathrm{~m}$-deep underground continuous walls. In order to prevent leakage between walls, the jet grouting columns $(0.8 \mathrm{~m}$-diameter $\times 35 \mathrm{~m}$-depth $)$ for sealing curtain were applied outside the wall. Figure 7 briefly illustrates the construction procedure at the site. Given the risk of excavation failure caused by phreatic water and artesian water in the site, 14 relief wells (pumping wells) were arranged in the excavation. Dewatering started on December 21, 2010, and ended on January 9, 2012. From the third construction step, the water level in the site was maintained at about $2 \mathrm{~m}$ below each incremental level of the excavation simultaneously by dewatering.

In this excavation, no springs were found during the excavation in the beginning. However, a large amount of water would pour from the underground in two areas when the excavation depth came up to the $5 \mathrm{~m}$. The locations of two small springs were confirmed in the geotechnical engineering reconnaissance. The emission quantity of one spring had 600 cubic meters per day, and the other spring 


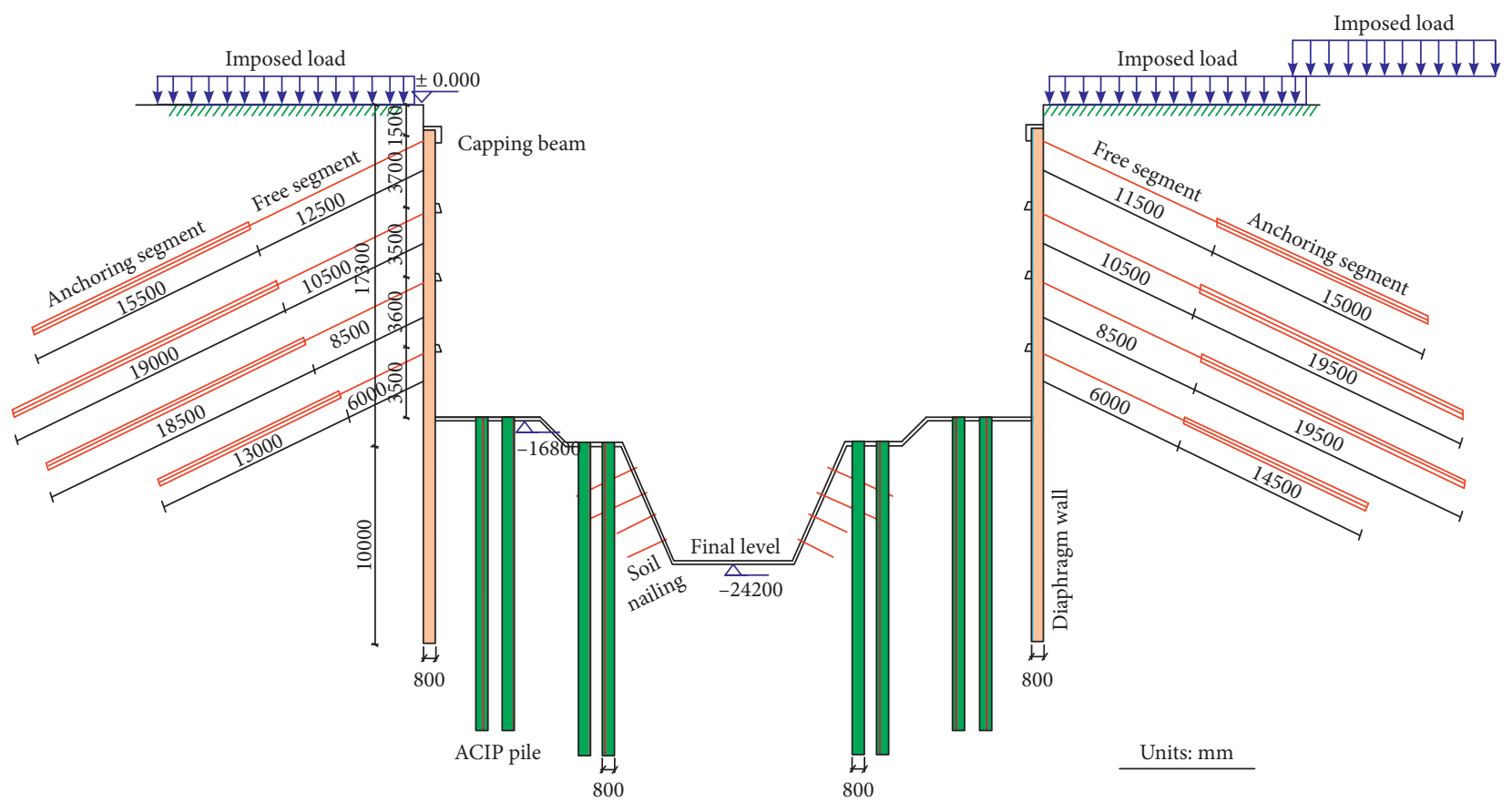

FIgURE 4: Support systems of typical section.

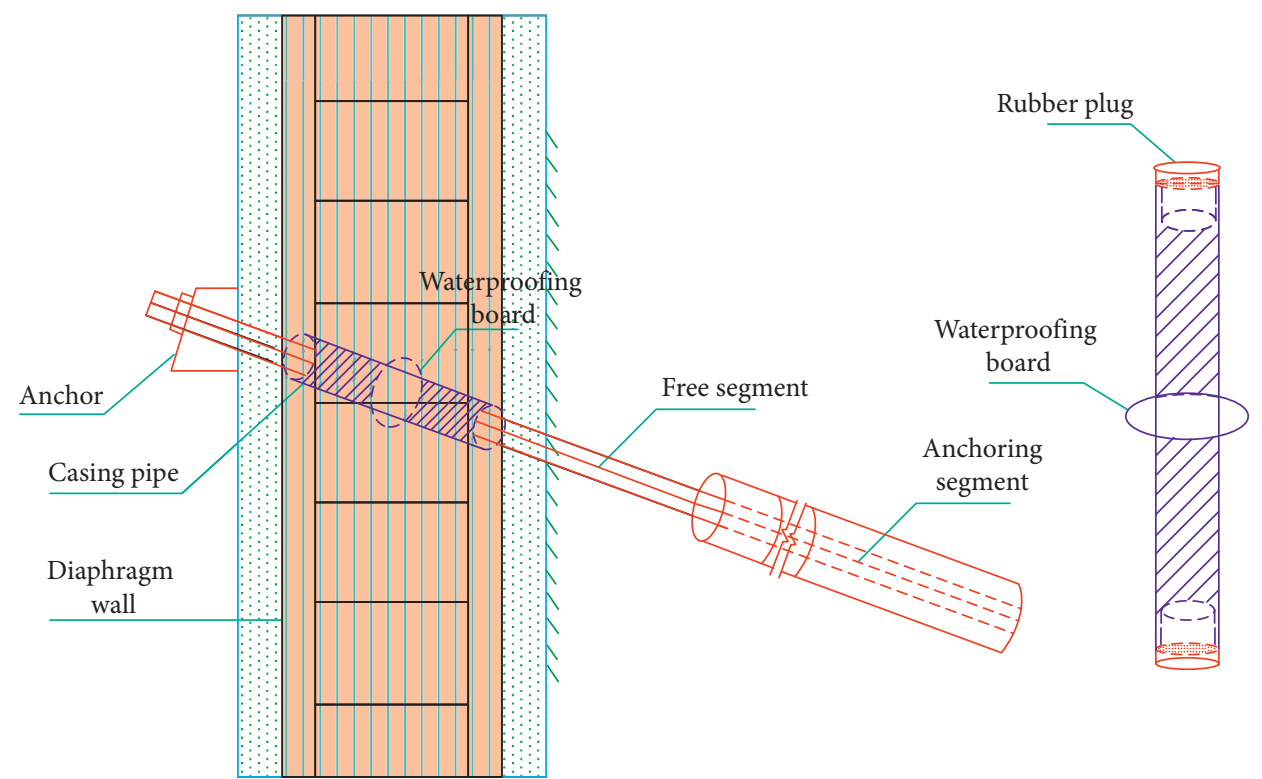

FIGURE 5: Connection node between the diaphragm wall and cable.

had 700 cubic meters. The quality of the spring water is presented in Table 1. The emission quantity and water pressure would damage the raft foundation. Therefore, two well point dewatering systems were installed nearby each spring in order to lower the groundwater levels. The precipitation volume of one pipe well was about 600 cubic meters per day. Figure 8 shows that the two pipe wells $(8 \mathrm{~m}$ in length and $600 \mathrm{~mm}$ in diameter) are placed nearby one spring in order to lower the water levels. The underground water level would be maintained at about $2 \mathrm{~m}$ below the final excavation level. To confirm design scheme and monitor the performance of this excavation for securing the safety of this project, various instruments were installed in situ. Figure 8 shows the instrumentations layout, which is used to monitor the behavior of this excavation, and Figure 9 shows the field monitoring instruments.

\section{Analysis of Field Measurements}

3.1. Typical Lateral Wall Deflections and Lateral Soil Movements. Figure 10 summarizes the lateral wall deflections at L1, L2, L3, L4, as well as the lateral soil 


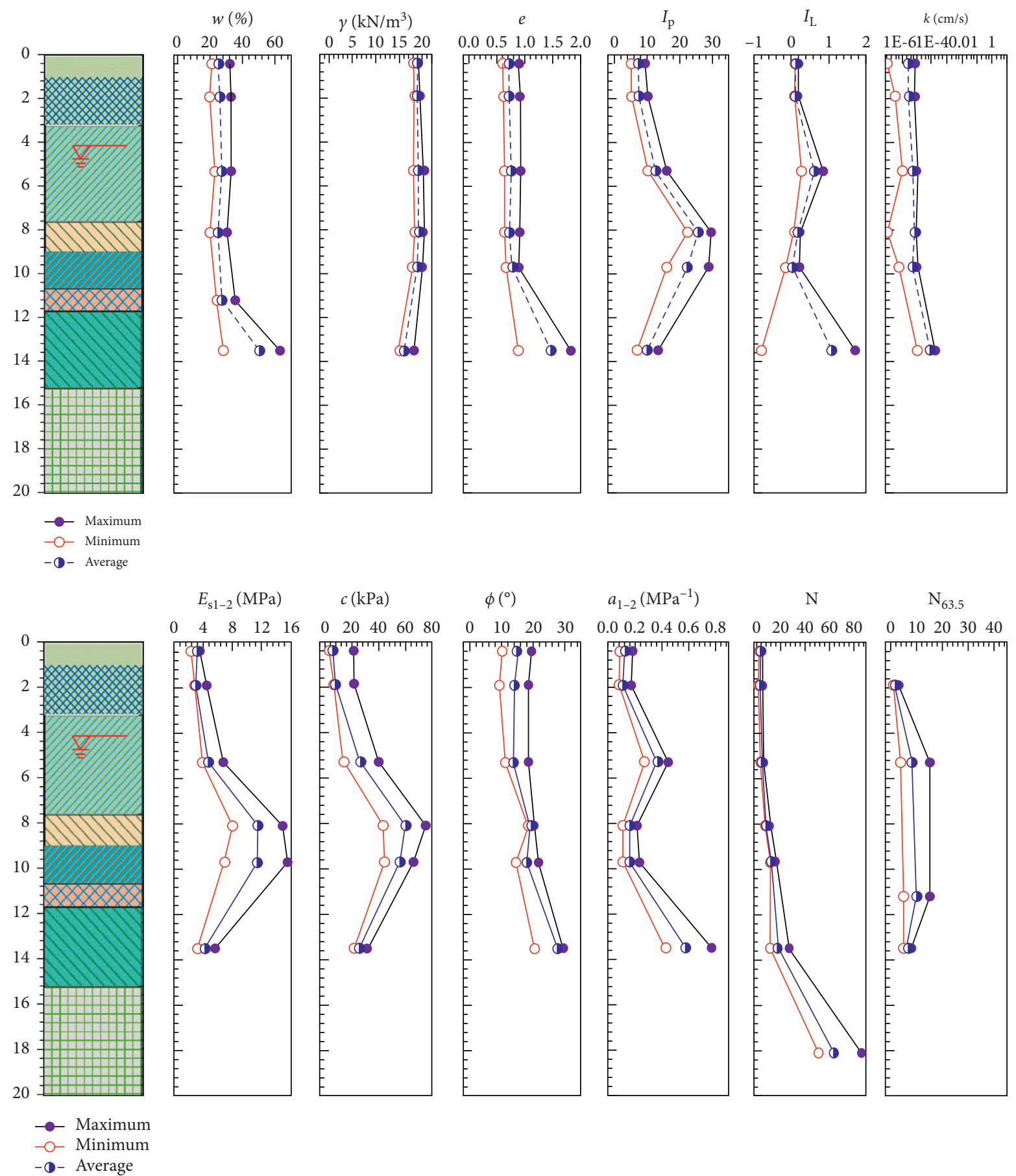

Figure 6: Soil profiles and geotechnical parameters.

movements at L5, L6, L7, L8. As the excavation proceeded to the $24.2 \mathrm{~m}$ (the final level), both the wall deflections and lateral soil movements gradually stabilized and came to the maximum. According to the deflections curve of L1, L2, L3, L4, it is noticed that the lateral deflections increase gradually with the excavation construction from stage 3(a) to stage 13 . From Figure 10(a), it is observed that the displacement of the upper portion in diaphragm walls is bigger than the lower portion. By further examination, the maximum deflections of L1, L2, L3 are 12 16 $\mathrm{mm}$ while the maximum deflection of
L4 is $32 \mathrm{~mm}$, which is $0.1 \% H_{\mathrm{e}} \sim 0.2 \% H_{\mathrm{e}}$ of the excavation depth. It can be concluded that the maximum deformation of L4 is twice bigger than L1, L2, L3. This discrepancy can be mainly ascribed to the fact that the grouting injection reinforcement is applied to the water leakage along the cable holes at L4. Due to the high water level in south segment, a large amount of water outflow from the four rows of anchor holes. In order to avoid affecting the construction of foundation pit because of the water leakage, 7 tons of cement was used in the grouting injection reinforcement for water 


\begin{tabular}{|c|c|c|c|c|c|c|c|c|c|c|c|c|c|c|c|c|c|c|c|c|c|}
\hline \multicolumn{5}{|c|}{ Actual project phases } & \multicolumn{17}{|c|}{ Calendar plan } \\
\hline Stage & Description & Start date & End date & Duration & Aug & Sep & Oct & Nov & Dec & Jan & Feb & Mar & Apr & May & Jun & Jul & Aug & Sep & Oct & Nov & Dec \\
\hline 1 & Construct the diaphragm walls & Aug. 22, 2010 & Nov. 22, 2010 & 90 & & $E 2$ & 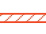 & ש & & & & & & & & & & & & & \\
\hline 2 & $\begin{array}{l}\text { Construct the rotary jet mixing } \\
\text { pile for sealing curtain }\end{array}$ & Nov. 22,2010 & Dec. 21,2010 & 30 & & & & & 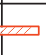 & & & & & & & & & & & & \\
\hline 3 (a) & $\begin{array}{c}\text { Dewater to } 4.4 \mathrm{~m} \text {, excavate soil to } \\
\text { level } 1\end{array}$ & Dec. 21,2010 & Jan. 27, 2011 & 36 & & & & & & 7 & & & & & & & & & & & \\
\hline $3(\mathrm{~b})$ & Drill for L1 cables & Jan. 27,2011 & Feb. 01, 2011 & 5 & & & & & & & 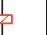 & & & & & & & & & & \\
\hline 4 & Construct and tension L1 cables & Feb. 01, 2011 & Feb. 10, 2011 & 10 & & & & & & & $\square$ & & & & & & & & & & \\
\hline 5 (a) & $\begin{array}{c}\text { Dewater to } 7.8 \mathrm{~m} \text {, excavate soil } \\
\text { to level } 2\end{array}$ & Feb. 10, 2011 & Feb. 21, 2011 & 11 & & & & & & & 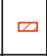 & & & & & & & & & & \\
\hline 5 (b) & Drill for $\mathrm{L} 2$ cables & Feb. 21, 2011 & Feb. 25, 2011 & 5 & & & & & & & $\square$ & & & & & & & & & & \\
\hline 6 & Construct and tension L2 cables & Feb. 25, 2011 & Mar. 07, 2011 & 11 & & & & & & & & 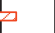 & & & & & & & & & \\
\hline 7 (a) & $\begin{array}{c}\text { Dewater to } 12 \mathrm{~m} \text {, excavate soil } \\
\text { to level } 3\end{array}$ & Mar. 07, 2011 & Mar. 17, 2011 & 11 & & & & & & & & $\square$ & & & & & & & & & \\
\hline 7 (b) & Drill for L3 cables & Mar. 17, 2011 & Mar. 22, 2011 & 6 & & & & & & & & $\square$ & & & & & & & & & \\
\hline 8 & Construct and tension L3 cables & Mar. 22, 2011 & Apr. 03, 2011 & 11 & & & & & & & & & 焉 & & & & & & & & \\
\hline 9 (a) & $\begin{array}{l}\text { Dewater to } 16 \mathrm{~m} \text {, excavate soil } \\
\text { to level } 4\end{array}$ & Apr. 03, 2011 & Apr. 15, 2011 & 12 & & & & & & & & & $\square$ & & & & & & & & \\
\hline 9 (b) & Drill for L4 cables & Apr. 15, 2011 & Apr. 20, 2011 & 6 & & & & & & & & & $\square$ & & & & & & & & \\
\hline 10 & Construct and tension L4 cables & Apr. 20, 2011 & May. 01, 2011 & 11 & & & & & & & & & & & & & & & & & \\
\hline 11 & $\begin{array}{c}\text { Dewater to } 18.8 \mathrm{~m} \text {, excavate soil } \\
\text { to level } 5\end{array}$ & May. 01, 2011 & Jun. 12, 2011 & 41 & & & & & & & & & & & 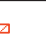 & & & & & & \\
\hline 12 & $\begin{array}{c}\text { Dewater to } 26.2 \mathrm{~m} \text {, excavate soil } \\
\text { to final level }\end{array}$ & Jul. 12, 2011 & Aug. 12, 2011 & 30 & & & & & & & & & & & & $W$ & ש & & & & \\
\hline 13 & Construct foundation slab & Aug. 12, 2011 & Dec. 12, 2011 & 120 & & & & & & & & & & & & & & & & & $\theta$ \\
\hline
\end{tabular}

FIgURE 7: Schedule of construction procedure.

TABLE 1: The quality of the spring water in Jinan city $(\mathrm{mg} / \mathrm{L})$.

\begin{tabular}{lcccccccccc}
\hline Site & Month & Salinity & $\mathrm{Ca}^{2+}$ & $\mathrm{Mg}^{2+}$ & $\mathrm{K}^{+}$ & $\mathrm{Na}^{+}$ & $\mathrm{CL}^{-}$ & $\mathrm{SQ}_{4}{ }^{2-}$ & $\mathrm{CQ}_{2}{ }^{2-}$ & $\mathrm{NQ}_{3}{ }^{-}$ \\
\hline \multirow{2}{*}{ Baotu Spring } & July & 594.8 & 90.2 & 22.1 & 1.1 & 35.3 & 51.42 & 77.06 & 300 & 52.7 \\
& October & 550.2 & 87.2 & 18.5 & 0.9 & 30.2 & 45.3 & 70.2 & 289.3 & 50 \\
\hline \multirow{2}{*}{ Pearl Spring } & July & 703.9 & 86.9 & 21.4 & 1.5 & 65 & 94.1 & 125.9 & 257.5 & 43.5 \\
& October & 468.4 & 82.2 & 16.1 & 0.8 & 35.7 & 50.4 & 92.8 & 237.7 & 25.5 \\
\hline \multirow{2}{*}{ Black Tiger Spring } & July & 646.1 & 122.2 & 23.1 & 0.5 & 18.6 & 54.9 & 87.3 & 296.9 & 40.2 \\
& October & 586.3 & 106.1 & 20.4 & 0.4 & 14.3 & 39.6 & 80.5 & 274.1 & 39.6 \\
\hline \multirow{2}{*}{ Five-Dragon-Pool Spring } & July & 753.3 & 142.1 & 32.9 & 0.7 & 25.7 & 82.8 & 121.5 & 325.8 & 83.2 \\
& October & 723.5 & 140.5 & 27.8 & 0.5 & 22.8 & 71.6 & 99.6 & 290.9 & 79.2 \\
\hline \multirow{2}{*}{ This study } & July & 582.3 & 85.6 & 20.1 & 1.2 & 32.2 & 50.3 & 70.1 & 285 & 51.2 \\
& October & 576.2 & 75.2 & 17.3 & 0.8 & 28.3 & 50.1 & 53.2 & 270.2 & 43.2 \\
\hline
\end{tabular}

leakage. Enormous pressure on the diaphragm wall was generated from the grouting, so that the deflection of the L4 was bigger. Figure 10(b) shows that deformation law of lateral soil movements is the same as the wall deflection law. Lateral soil movements also increase gradually step by step during the excavation construction. In the meantime, the maximum deformation of L8 is twice bigger than L5, L6, L7 $\left(0.07 \% H_{\mathrm{e}} \sim 0.14 \% H_{\mathrm{e}}\right)$, which is attributed to the grouting injection reinforcement. As a consequence, it is necessary to monitor the deformation of retaining structure as well as lateral soil movements during construction to ensure the safety of the excavation.
3.2. Typical Lateral Wall Deflections and Ground Settlement. Figure 11(a) shows the lateral wall deflection and ground settlement at the west segment. The lateral wall deflection and ground settlement increase gradually with the depth of excavation. The maximum wall deflection appears at the upper part of the wall and the maximum ground settlement appears beside the excavation. The maximum wall deflection is about $16 \mathrm{~mm}$, while the maximum ground settlement is $13 \mathrm{~mm}$. Therefore, the maximum ground settlement is a little less than the maximum wall deflection. Figure 11(b) also shows the lateral wall deflection and ground settlement at the south segment. The growth trend of this segment 


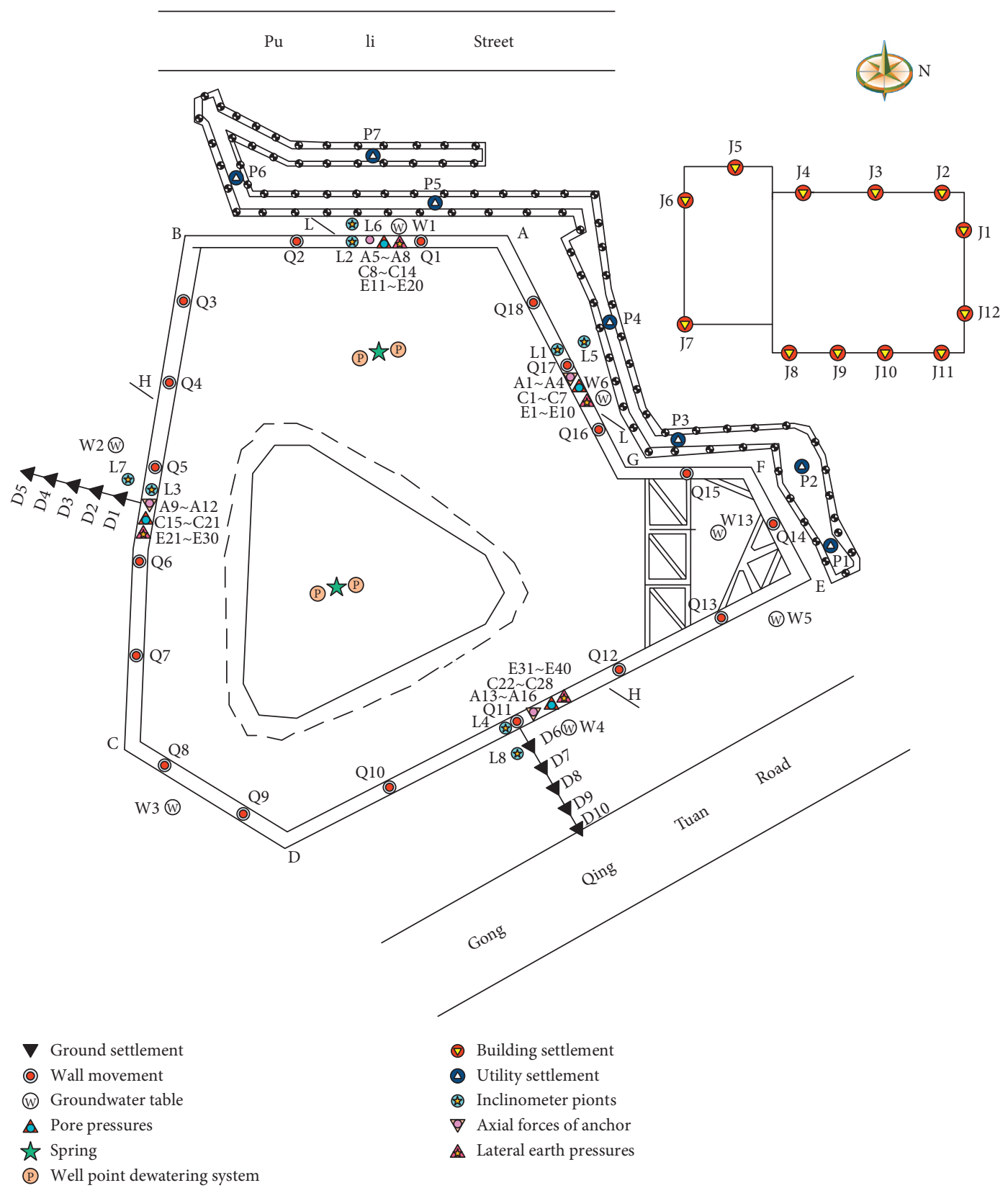

FIGURE 8: Layout of instrumentation gauges.

deformation is similar with the west segment. The maximum wall deflection is about $33 \mathrm{~mm}$, while the maximum ground settlement is $28 \mathrm{~mm}$. Figure 11 illustrates the ultima deformation of excavation behavior is far from the original calculation. It can be concluded that the diaphragm walls have significant effects in reducing wall deflection and ground settlement.

3.3. Horizontal Deflections of the Top Wall. The capping beam monitoring points are shown in Figures 8 and 12 presents the horizontal displacement about eighteen points. From Figure 12, it is observed that the performances of the capping beam have three stages: slow increasing section, linear increasing section, and stable increasing section. The wall deflections show in slow increasing tendency from stage $3(\mathrm{a})$ to stage $7(\mathrm{a})$. The maximum deflection only comes to $10 \mathrm{~mm}$ before the soil layer up to $10 \mathrm{~m}$. In contrast to other similar excavations, the deflections are much smaller and such a phenomenon can probably be explained by the superiority of the diaphragm wall. The wall deflections almost increased linearly with time from stage 9(a) to stage 11 . At this point, the depth of the peripheral part in the excavation reached up to $16.8 \mathrm{~m}$. The linear increasing trend would be attributable to the soil pressure and water pressure. Q10, Q11, and Q12 were located in the south of the excavation. However, there was a scrapped air-raid shelter on the south side of the excavation. A lot of spring water from Qianfo Mountain flowed into the air-raid shelter. Therefore, a large amount of the spring water flowed into the excavation 


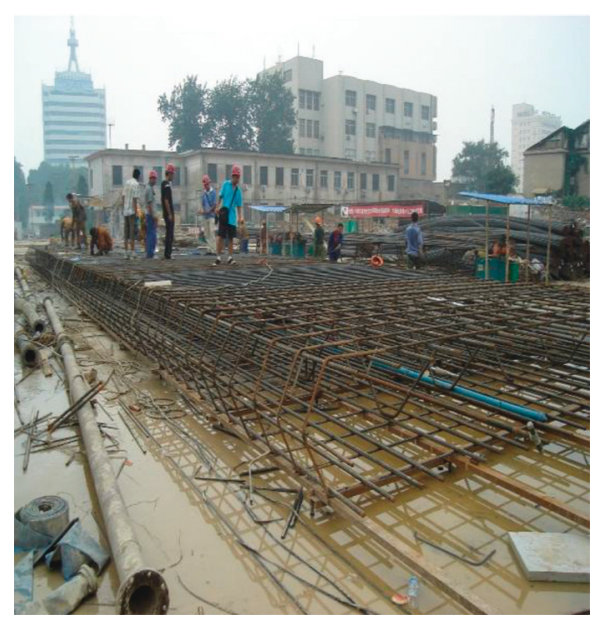

(a)

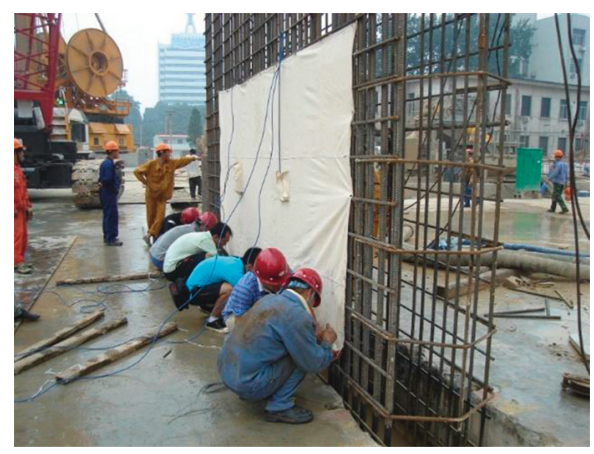

(c)

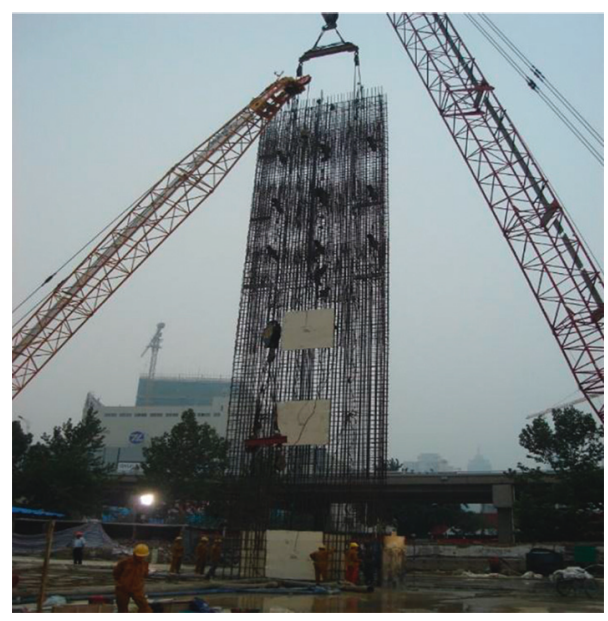

(b)

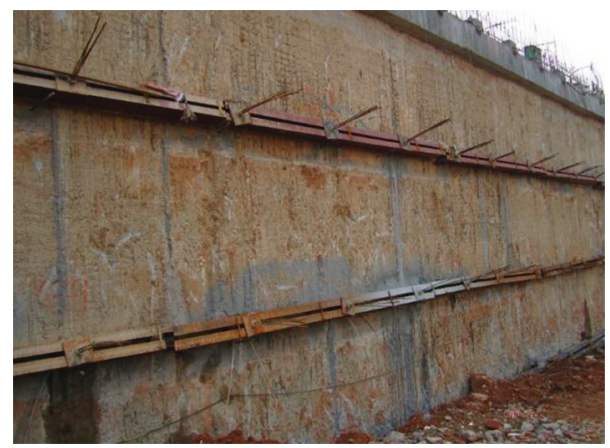

(d)

Figure 9: Field monitoring instruments. (a) Inclinometer and strain gauge. (b) Earth pressure cells. (c) Piezometers. (d) Anchor strain gauge.

through the anchor hole from the air-raid shelter in stage 9. In order to prevent water from flowing into the excavation, a large amount of cement mortar was injected into the anchor hole by means of high-pressure grouting in stage 9. Consequently, the wall deflection of Q10, Q11, and Q12 had rapid increments due to high-pressure grouting. Figure 12 also indicates that most of the diaphragm wall deflections occur before the base slabs are completed and the soilstructure system almost reaches the stable state after the completion of the base slabs.

3.4. Maximum Lateral Wall Deflection. Figure 13 indicates the relationship between the maximum lateral wall deflection $\left(\delta_{\mathrm{h}, \max }\right)$ and excavation depth. To compare the deformation performance of different excavation cases, many published case histories of excavations in soft to stiff clays are collected. From the data points of $\delta_{\mathrm{h} \text {,max }}(\mathrm{L} 1, \mathrm{~L} 2, \mathrm{~L} 3$, L4), the results show that the maximum lateral wall deflections in this project are between 0.07 percent and 0.18 percent of the excavation depth. By comparing excavations case histories, it is observed that the maximum lateral wall deflection in this study is similar to that in Dublin-Jervis, London, and Boston due to the similar favorable soil conditions $[21,39]$. In addition, it was observed that most of the measured $\delta_{\mathrm{h}, \max }$ values in Oslo, Singapore, San Francisco, and Chicago were between 0.67 percent and 2.2 percent of the excavation depth, which were above the range of 0.19 percent and 0.95 percent of the excavation depth measured in Shanghai, Taipei, Iran, and Boston [7, 26, 40, 41]. The excavations in Oslo, Chicago, Singapore, San Francisco, Shanghai, Taipei, and Boston [7,40-45] were all constructed in soft soils. This outcome was also attributed to the fact that the excavations in Shanghai, Iran, Taipei, and Boston $[7,26,40,41]$ were usually supported by stiff diaphragm walls, while the excavations in Singapore, Oslo, and San Francisco were supported by contiguous bored pile walls and sheet piles.

3.5. Ground Surface Settlement. Figure 14(a) presents the relationship between the normalized ground settlements $\left(\delta_{\mathrm{v}} /\right.$ $\left.H_{\mathrm{e}}\right)$ and normalized distances for this study $\left(d / H_{\mathrm{e}}\right)$. The ground settlements data plots a convex profile in the west segment and the south segment. This shows that the maximum ground settlements appear right behind the diaphragm wall. The ground settlement decreases rapidly with distance from the excavation pits and the ground settlements in the south segment are greater than the settlements in the west segment. To better understand excavation behaviors in Jinan clay, published case histories $[10,21,25,46]$ are also included for comparison. The comparison of the excavation 

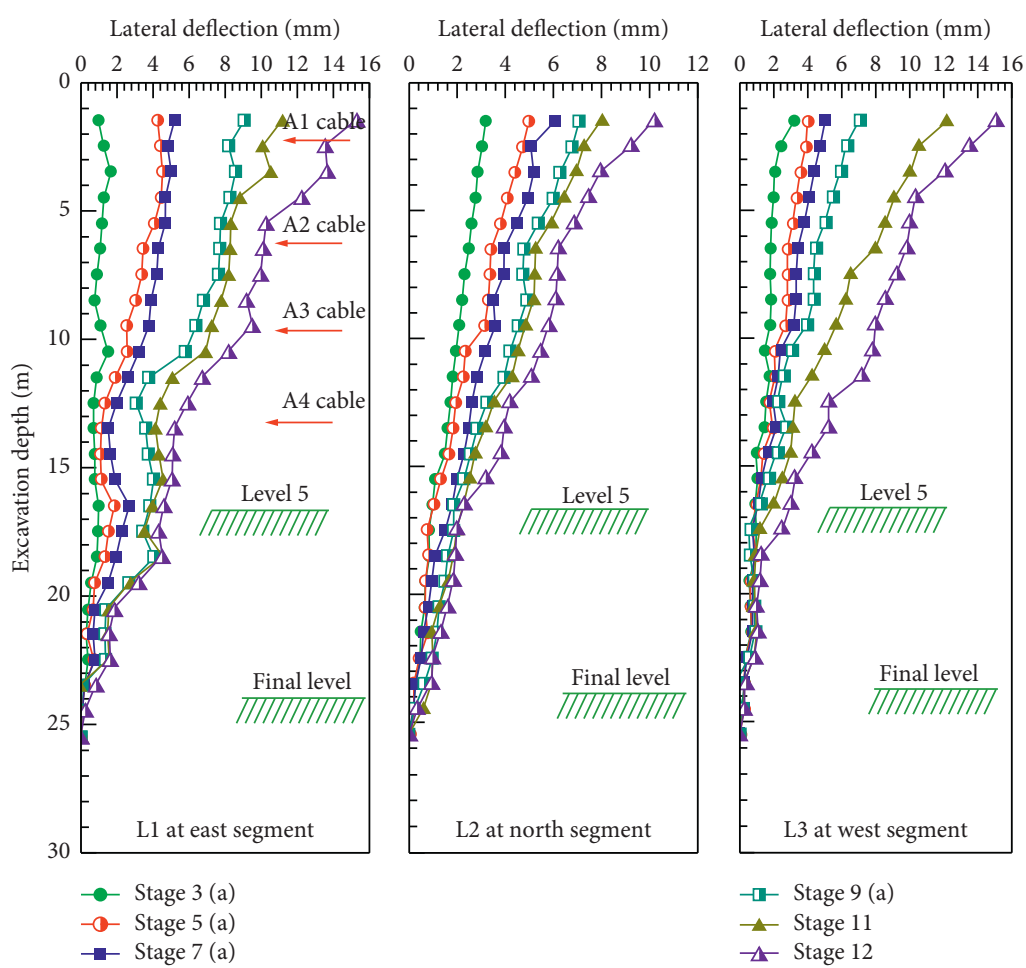

Lateral deflection $(\mathrm{mm})$

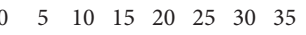

(a)
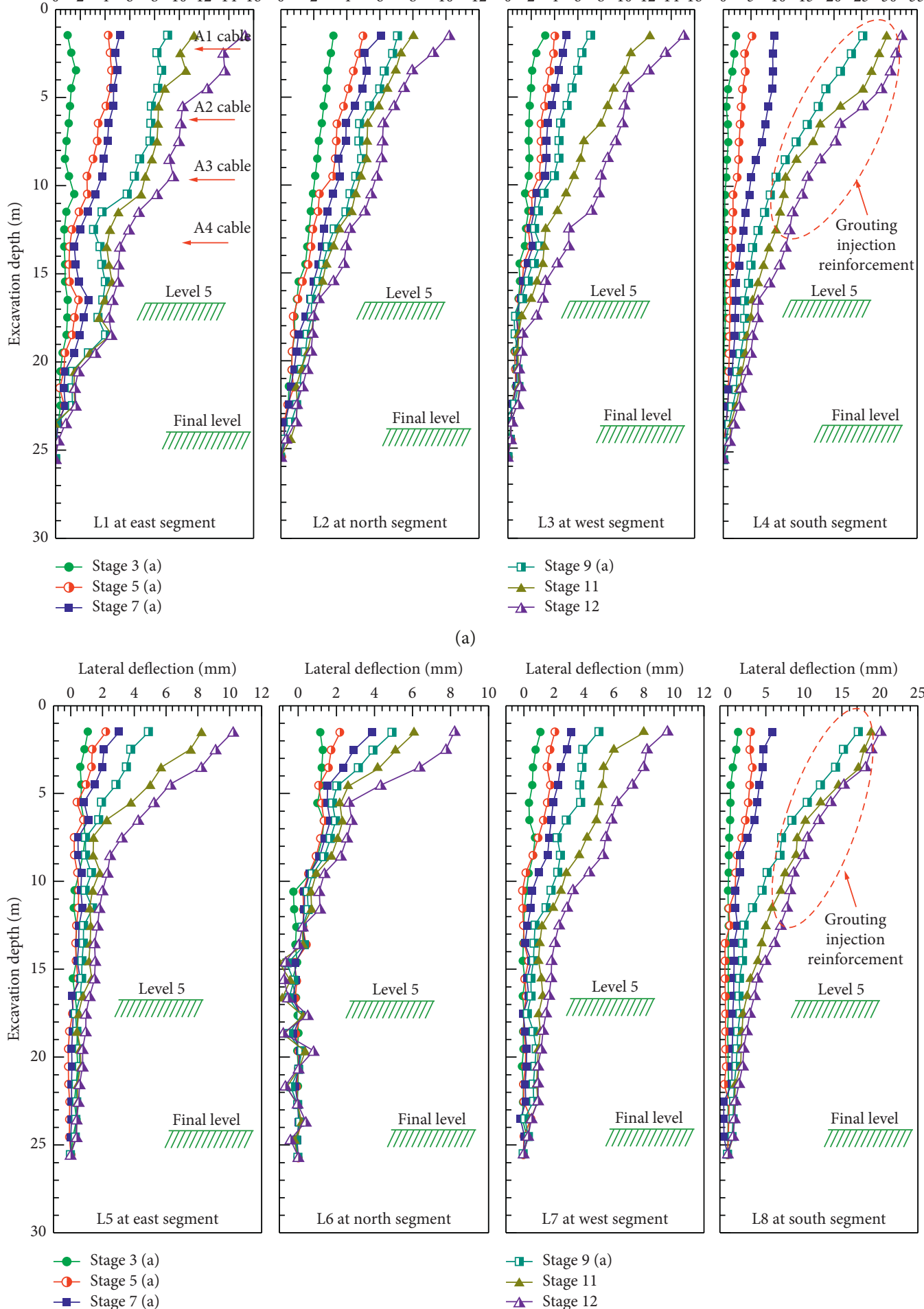

Lateral deflection $(\mathrm{mm})$

Lateral deflection $(\mathrm{mm})$

Lateral deflection $(\mathrm{mm})$

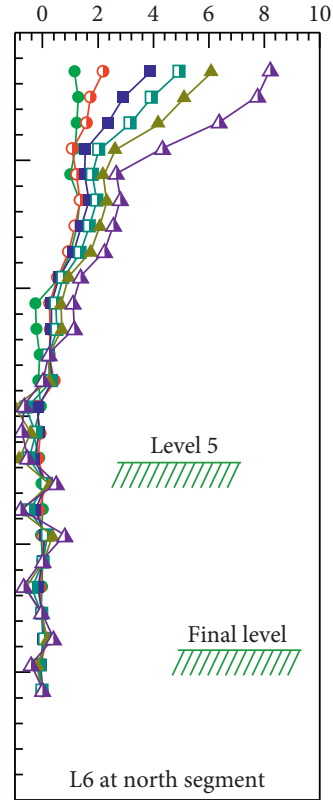

$\begin{array}{llllllll}0 & 0 & 2 & 4 & 6 & 8 & 10 & 12\end{array}$

$\begin{array}{llllll}0 & 5 & 10 & 15 & 20 & 25\end{array}$
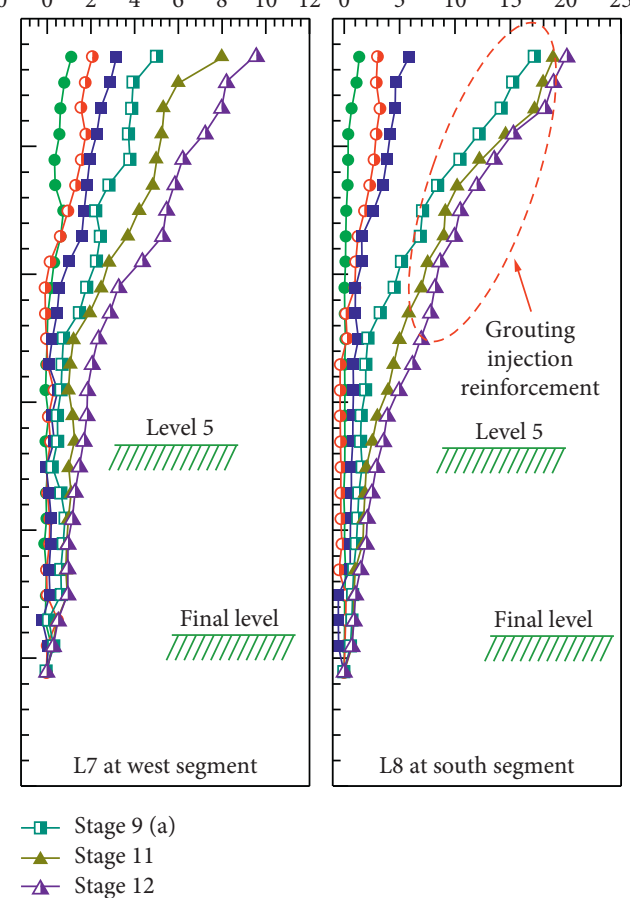

-4 Stage 12

(b)

Figure 10: Horizontal deformations of wall deflections and lateral soil movements. (a) The lateral wall deflections. (b) The lateral soil movements.

in Jinan and those reported in literature show that these study data are consistent with the stiff clay and silty sand and the stiff to hard clay [25, 46]. The data also fall within O'Rourke [29] profile for middle-dense to dense sand and
Hashash et al. [21] profile for medium stiff clay, but far away from Zone III of Peck [10] for very soft to soft clay. The Chicago glacial clay falls mainly within Zone I of Peck [10], while the Oslo clay and the sand [25] fall within Zone II of 


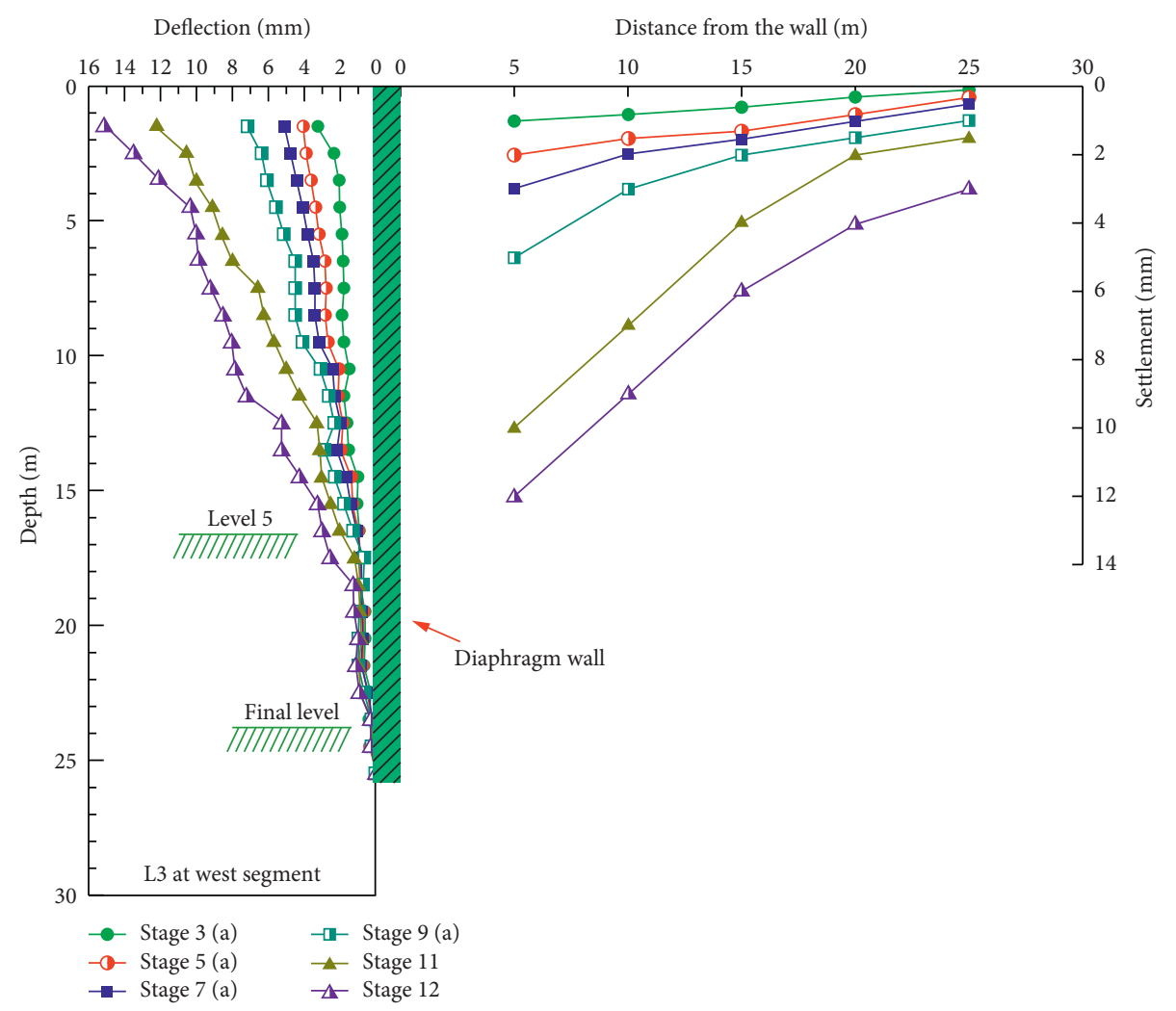

(a)

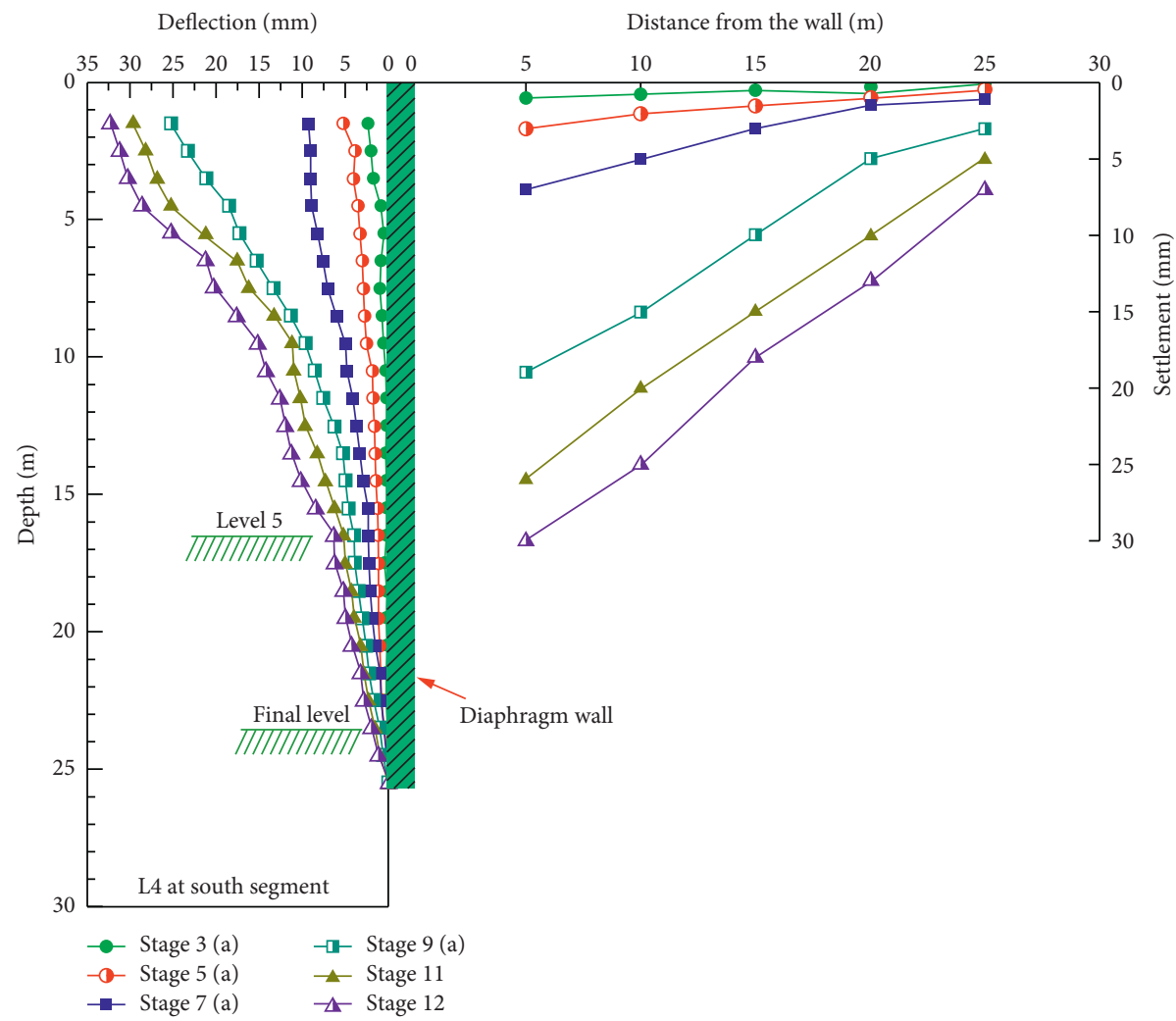

(b)

Figure 11: Lateral wall deflection and ground settlement. (a) L3 at the west segment. (b) L4 at the south segment. 


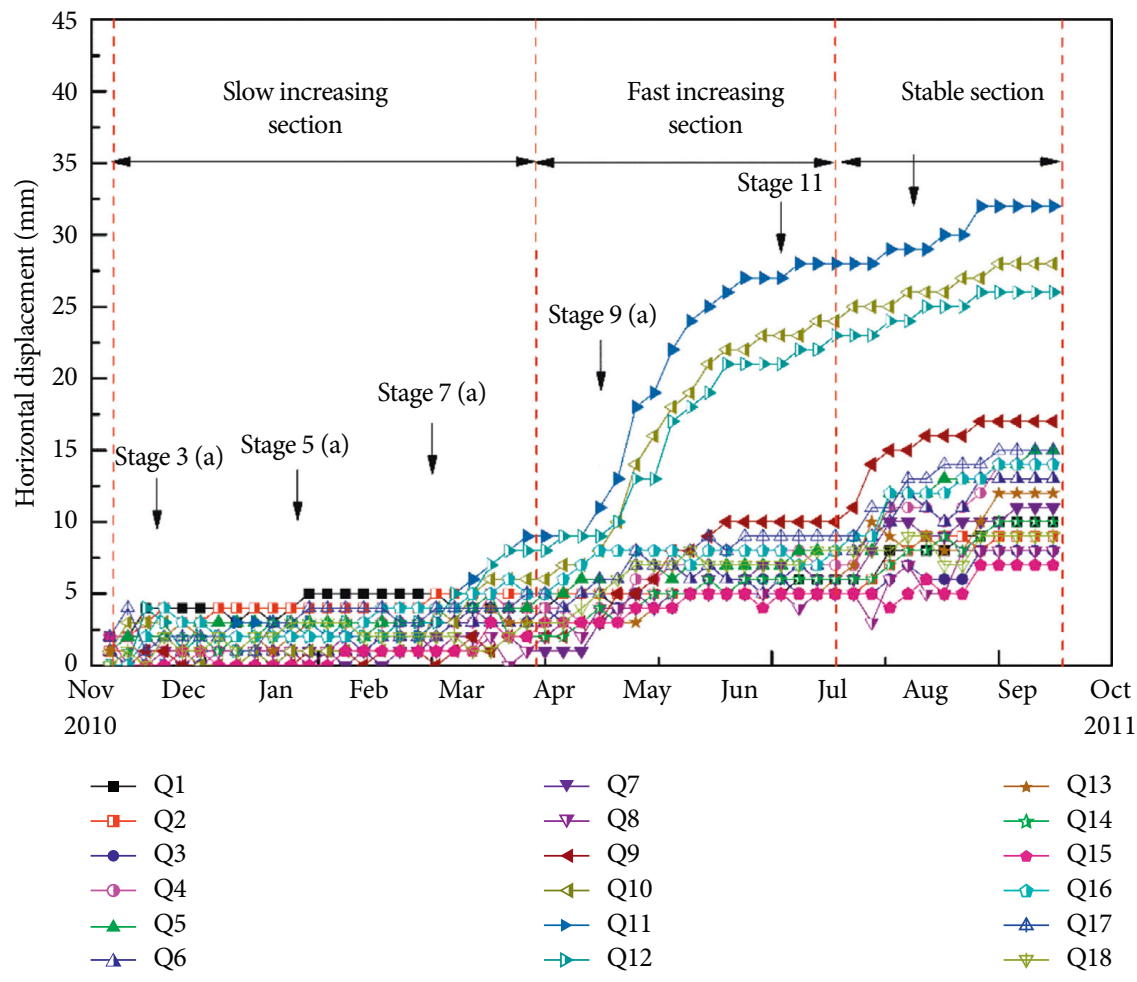

FIGURE 12: Horizontal displacement of top of wall during excavation.

Peck [10]. This comparison proves that polygonal excavation supported by diaphragm walls is capable of suppressing excavation-induced movements in Jinan stiff clay. In sharp contrast to the stiff clay data, the ground settlements in soft clay vary in a large range.

Figure 14(b) plots the relationships between the normalized ground settlements, $\delta_{\mathrm{v}} / \delta_{\mathrm{v}, \max }$, and the distance ratio, $d / H_{\mathrm{e}}$, where $\delta_{\mathrm{v}}=$ ground settlement along the typical section; $\delta_{\mathrm{v}, \max }=$ maximum ground settlement at the same section behind the diaphragm wall; $d=$ distance away from the diaphragm wall; $H_{\mathrm{e}}=$ final excavation depth. In this figure, these case history documents in the literature $[3,21$, $32,34,46]$ are applied for comparison. From Figure 14(b), it can be concluded that the settlement distribution is bounded by a trapezoidal envelope. When $0 \leq d / H_{\mathrm{e}} \leq 0.9$, the maximum settlements take place; when $0.9<d / H_{\mathrm{e}} \leq 2.4$, a transition zone comes into being. The influence zone of this study is wider than Clough and O'Rourke [46] for stiff to hard clay and is narrower than Hashash et al. [21] for medium stiff clay and Wang et al. [34] for soft clay. Hsieh and $\mathrm{Ou}$ [3] pointed out the primary influence zone and secondary influence zone. When $d / H_{\mathrm{e}} \leq 2.0$, the primary influence zone occurs; when $2.0<d / H_{\mathrm{e}} \leq 4.0$, the secondary influence zone works out. Compared with Hsieh and $\mathrm{Ou}$ [3], the distribution ranges of the ground settlements in this study mainly fall within the primary influence zone. Figure 14(b) also shows that the range of the measured $\delta_{\mathrm{v}} /$ $\delta_{\mathrm{v}, \max }$ in this excavation is wider than the maximum settlements defined by Clough and O'Rourke [46]. Most of the measured $\delta_{\mathrm{v}} / \delta_{\mathrm{v} \text {, max }}$ lay between 0 and 0.6 in the top half of the figure. Compared with Tan and Wang $[11,30,31,32]$ and
Wang et al. [34], the measured $\delta_{\mathrm{v}} / \delta_{\mathrm{v}, \max }$ of these two case histories mainly lay between 0.4 and 0.9 in the bottom half of the figure. This discrepancy indicates that the excavationinduced settlements of stiff clay are larger than soft clay at the excavation preliminary stage. On the other hand, the significantly thick distribution of $\delta_{\mathrm{v}} / \delta_{\mathrm{v}, \max }$ in the top half of the figure also mainly derives from the favorable supporting system at this site. The settlement influence zone extends beyond $2.5 \mathrm{H}_{\mathrm{e}}$ from the pit for this project. In addition, this excavation case has narrower influence zones than Hashash et al. [21] for Boston stiff clay.

3.6. Relationship between the Maximum Ground Settlement and the Maximum Wall Deflection. Figure 15(a) illustrates the relationships between the maximum wall deflections, $\delta_{\mathrm{h}, \max }$, and the corresponding maximum ground settlements, $\delta_{\mathrm{v}, \mathrm{max}}$. Mana and Clough [44] summed up the relationship between the normalized maximum ground settlement and the maximum wall movement using the data from many excavation cases in San Francisco, Oslo, and Chicago. According to Mana and Clough [44], most of the excavations showed that the relationships fell between $\delta_{\mathrm{v}, \max }=0.5 \delta_{\mathrm{h}, \max }$ and $\delta_{\mathrm{v}, \max }=\delta_{\mathrm{h} \text {,max. }}$. Wallace et al. [45] and Ou et al. [40] also pointed out field data from excavations in Singapore and Taipei, respectively. Wallace et al. [45] investigated that the maximum ground settlement was larger than the maximum piles deflections in Singapore. Ou et al. [40] reported that the field data fell on the line $\delta_{\mathrm{v}, \max }=0.67$ $\delta_{\text {h,max. }}$ The field data from this study are compared with these data in Figure 15(a). For this excavation, the observed 


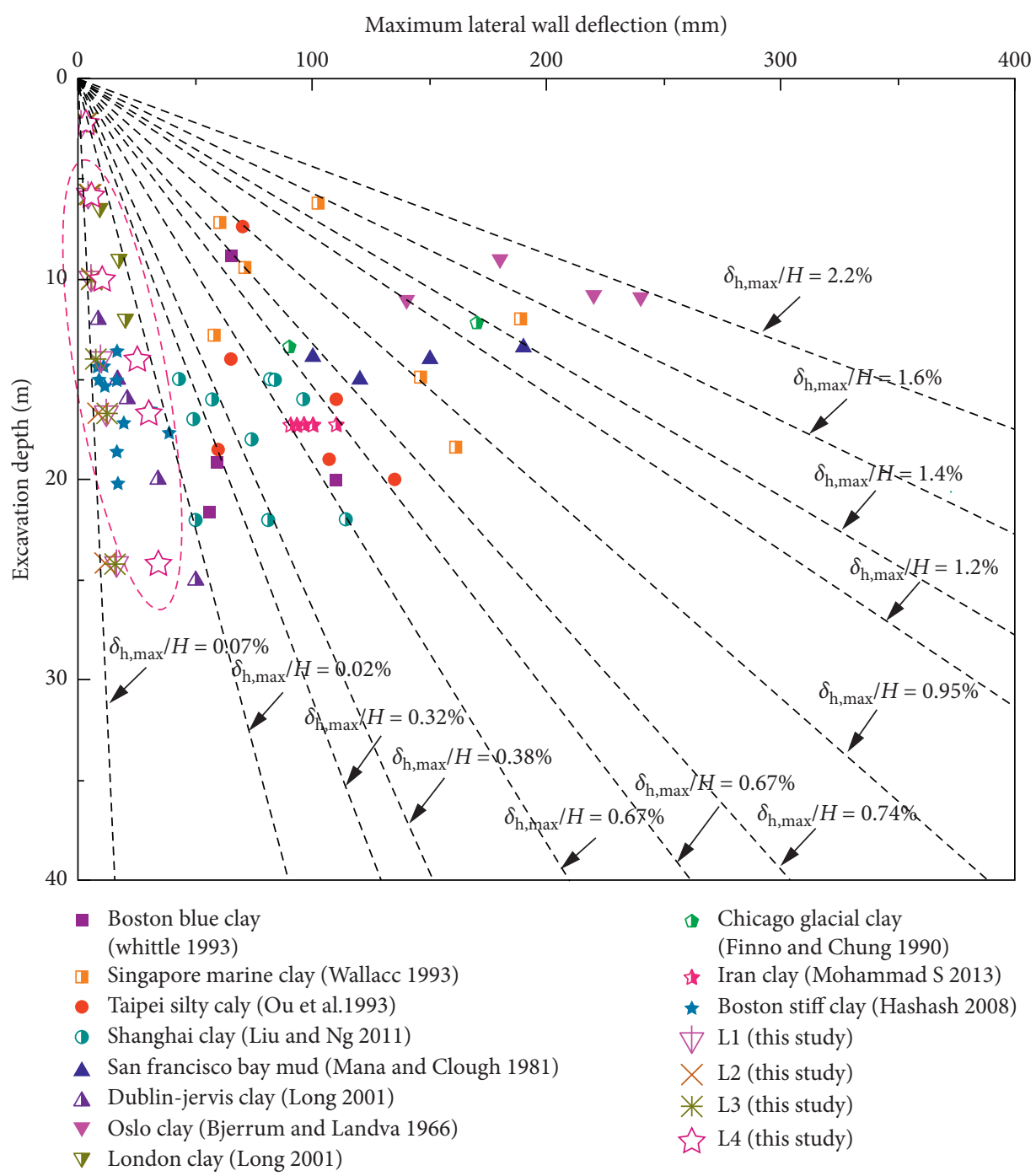

Figure 13: Maximum lateral wall deflections versus excavation depth.

relationships are between $\delta_{\mathrm{v}, \max }=0.67 \quad \delta_{\mathrm{h}, \max }$ and $\delta_{\mathrm{v}, \max }=\delta_{\mathrm{h}, \max }$, which shows that the maximum ground settlements $\delta_{\mathrm{v}, \max }$ are smaller than the maximum wall deflections $\delta_{\mathrm{h}, \max }$. These field data fall in the range of $\delta_{\mathrm{v}, \max }=(0.5-0.6) \delta_{\mathrm{h}, \max }$ as suggested by Mana and Clough [44] and are smaller than those of Wallace et al. [45]. The other excavation is supported by bored piles in Jinan as suggested by Zhang et al. [16]. According to Figure 15(b), the field data for the other excavation fall on the line $\delta_{\mathrm{v}, \max }=\delta_{\mathrm{h} \text {, max }}$, which is greater than this study. Therefore, the stiff diaphragm wall could better restrain the excavation deformation.

3.7. Lateral Earth Pressures on Diaphragm Wall. As shown in Figure 8, many earth pressure cells were observed on the diaphragm walls to monitor the total lateral earth pressures. The observation information and monitoring results are shown in Figure 16. Figure 16 compares the observed lateral earth pressures and the theoretical Rankine pressures from stage 3(a) to stage 12, respectively. As shown in Figure 16(a), the most monitoring data are between the theoretical $K_{\mathrm{a}}$ condition and theoretical $K_{\mathrm{o}}$ pressure. This behavior can be attributed to the fact that the wall has outward movement, which causes the lateral earth stress release. However, the measured earth pressures at $7 \mathrm{~m}$ are mainly larger than the theoretical $K_{\mathrm{o}}$ pressure. This might be accounted for by the fact that the soil behind the wall has inward movement because of the stiff cable. The braced cables cause the soil to move to the unexcavated side, so that the filed earth pressures are mainly larger. The maximum lateral active earth pressures above the excavation bases occur at a depth of $0.4 \mathrm{H}$. In addition, the filed earth pressures at $15 \mathrm{~m}$ are substantially smaller than the theoretical Rankine active earth pressure. There are two reasons. On the one hand, the soil behind the wall has larger creep deformation on account of the flabby strut, so that the lateral earth stress has a bigger relief. On the other hand, Rankine theory will not consider the friction between the soil and the diaphragm wall when the diaphragm wall surface is rough. Hence, the lateral earth pressure would be overestimated without considering the friction between the soil and diaphragm wall. As shown in 
Normalized distance behind retaining wall, $d / H_{\mathrm{e}}$

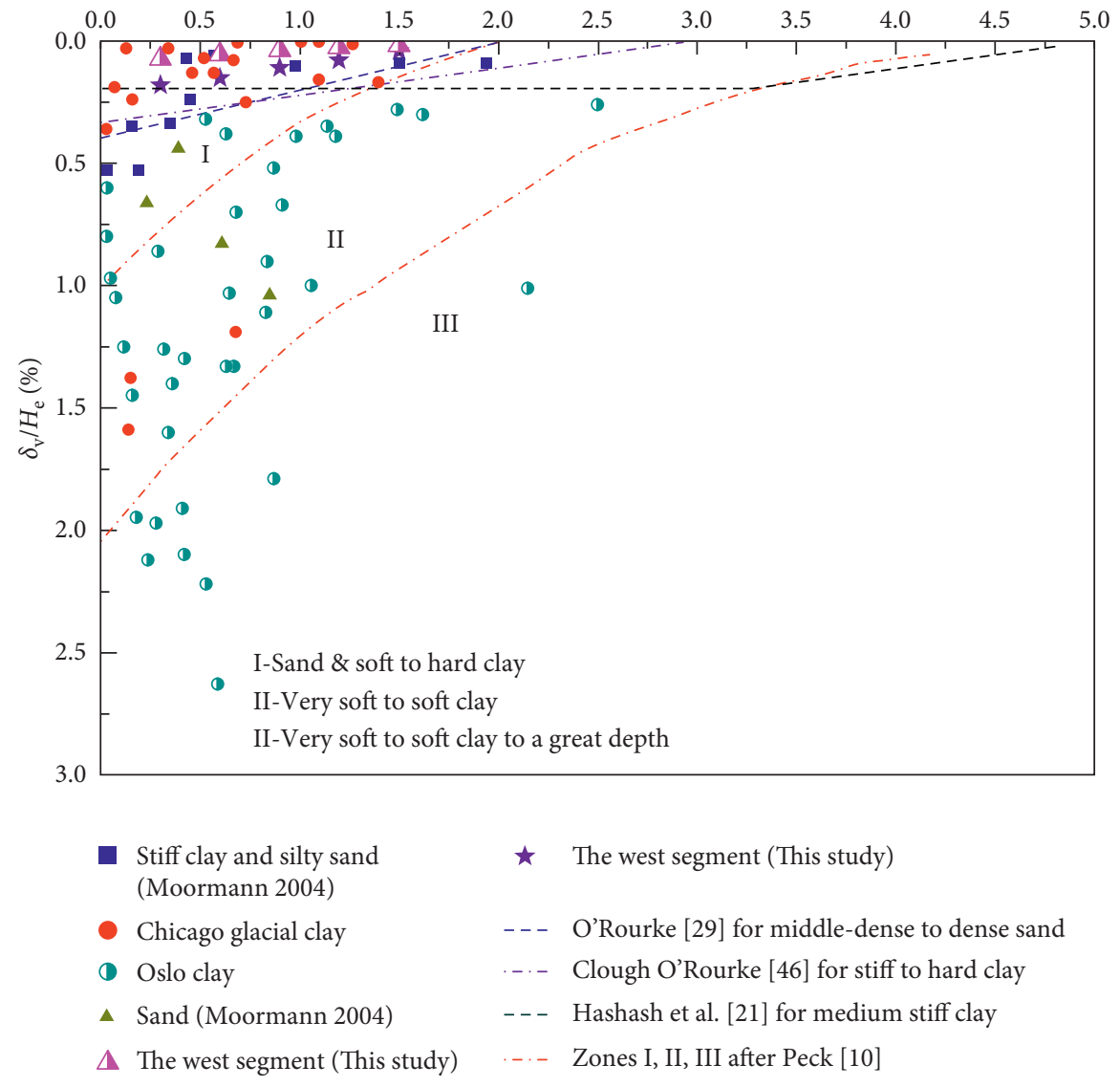

(a)
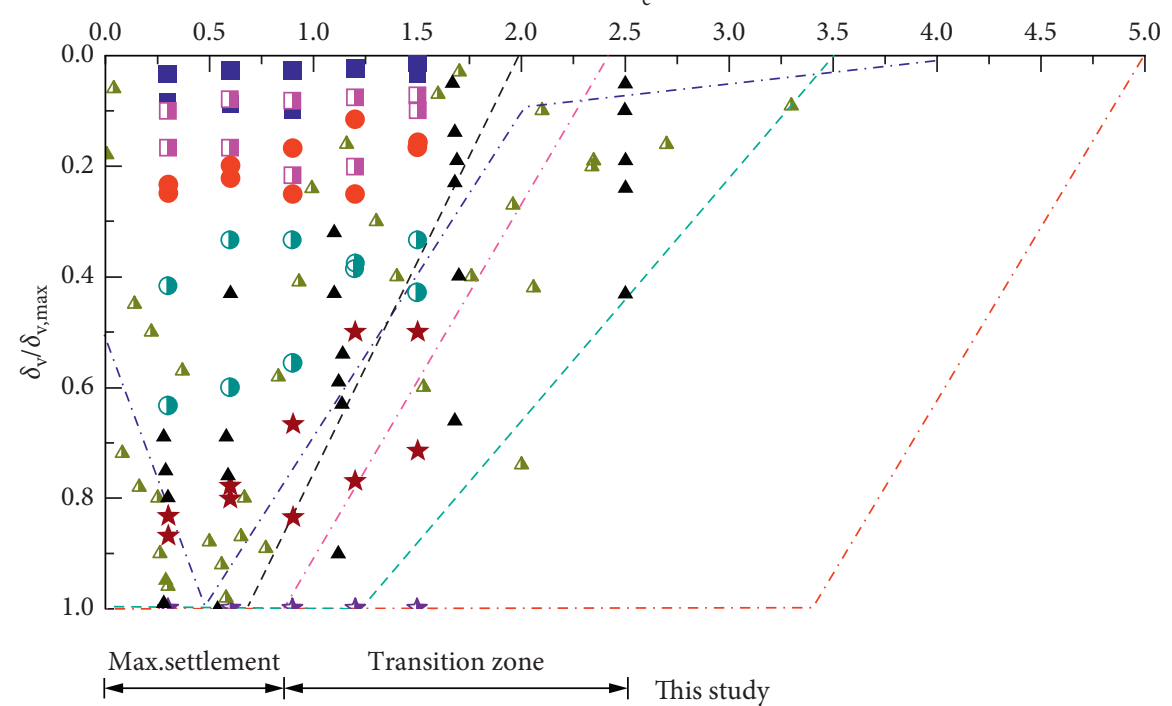

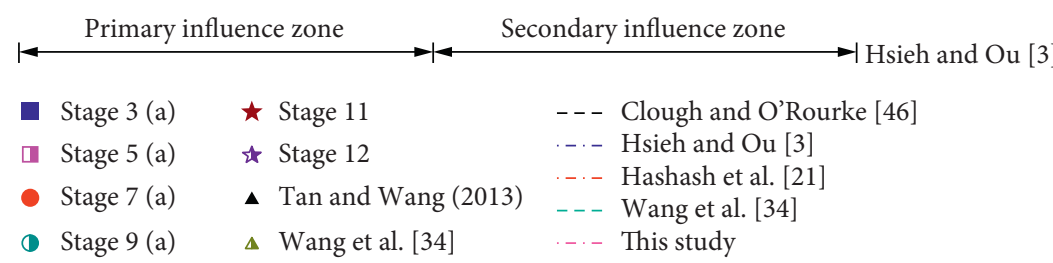

(b)

FIGURE 14: Observed ground settlement profiles versus those predicted by empirical methods. (a) Relationship between $\delta_{\mathrm{v}} / H_{\mathrm{e}}$ and $d / H_{\mathrm{e}}$. (b) Relationship between $\delta_{\mathrm{v}} / \delta_{\mathrm{v}, \max }$ and $d / H_{\mathrm{e}}$. 


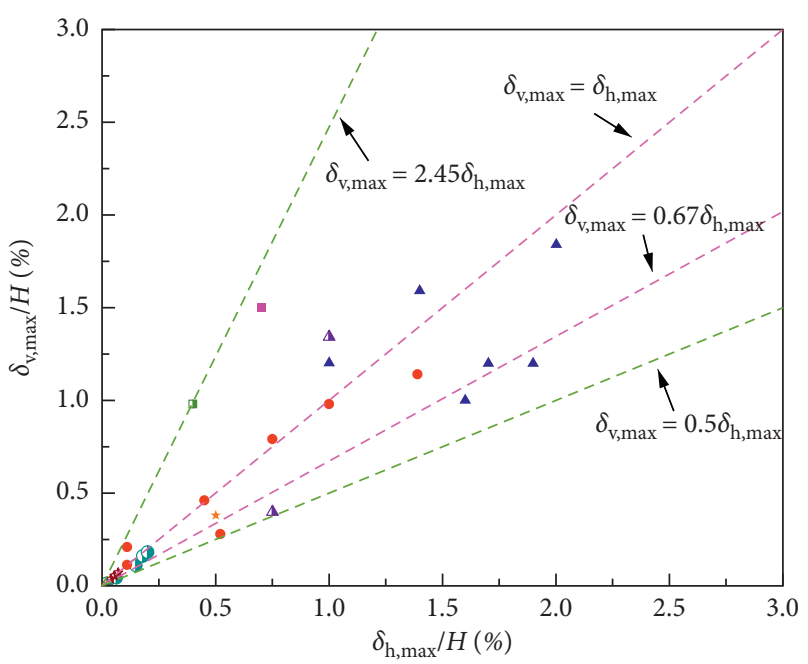

- This study

* Jinan

- San Francisco

$\triangle$ Oslo

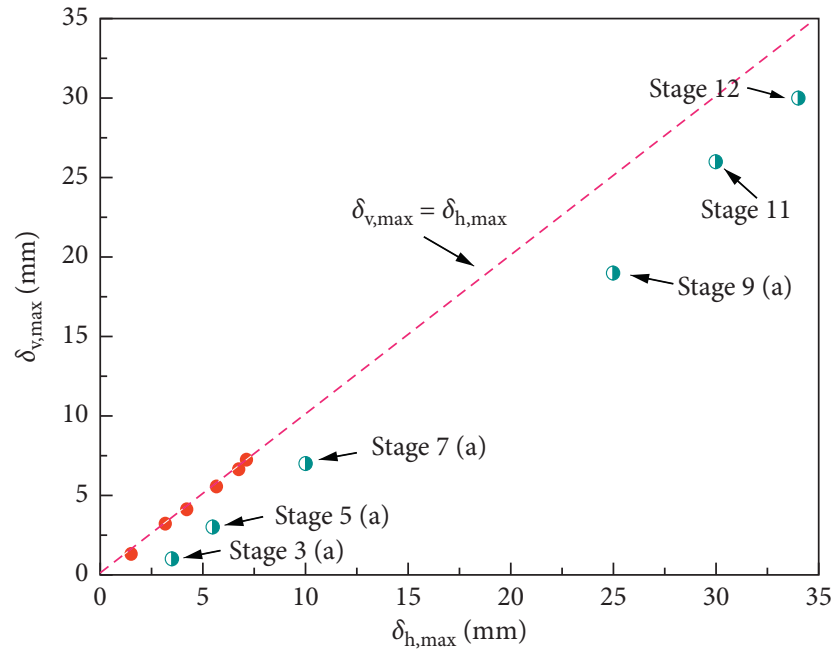

- This study

- Jinan

(b)

Figure 15: Relationship between the maximum ground settlement and the maximum piles deflection. (a) Combined cases date. (b) This study.
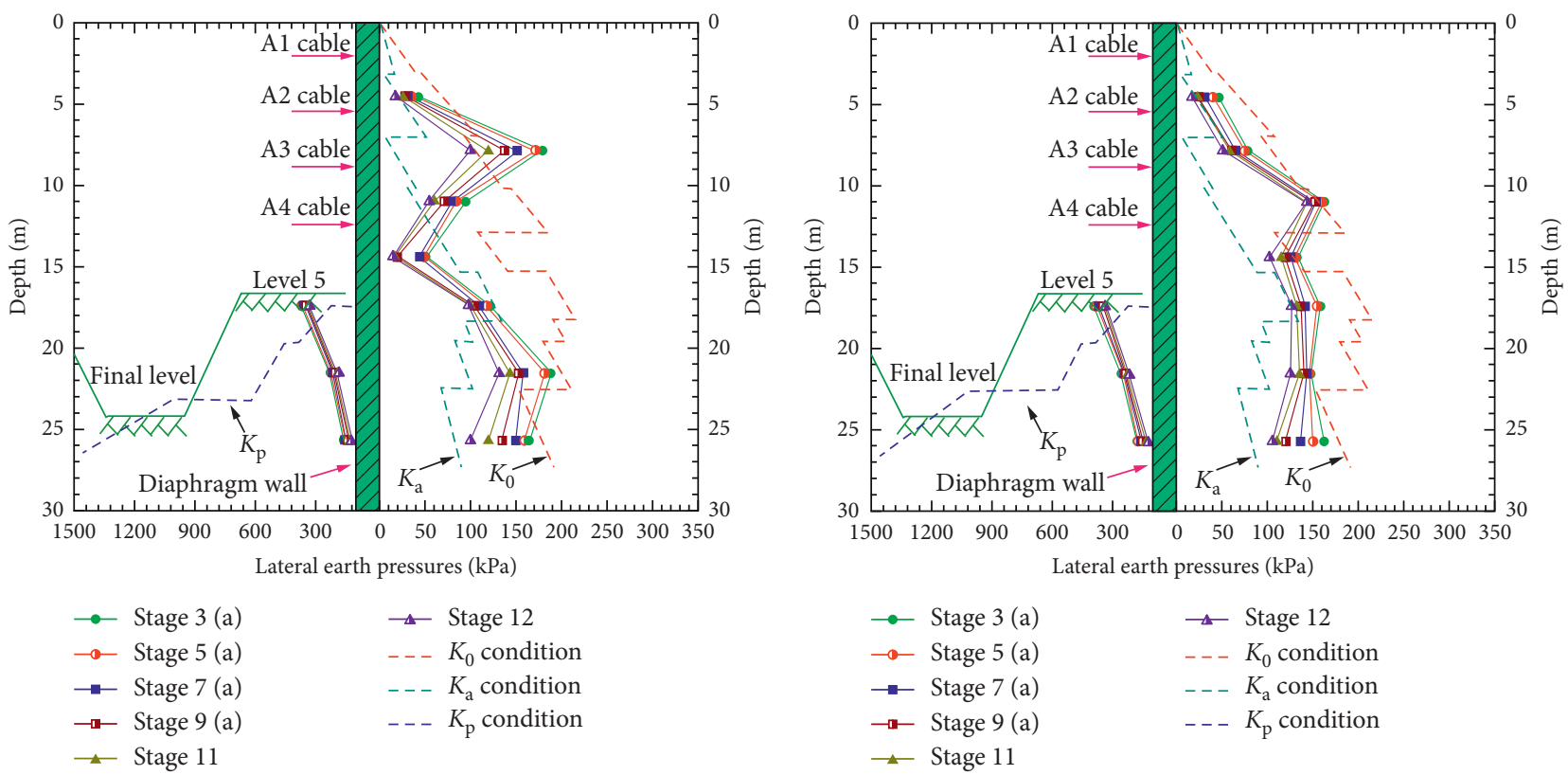

(a)

$$
\begin{aligned}
& -\triangle \text { Stage } 12 \\
& ---K_{0} \text { condition } \\
& ---K_{\mathrm{a}} \text { condition } \\
& ---K_{\mathrm{p}} \text { condition }
\end{aligned}
$$

(b)

FIgUre 16: Continued. 

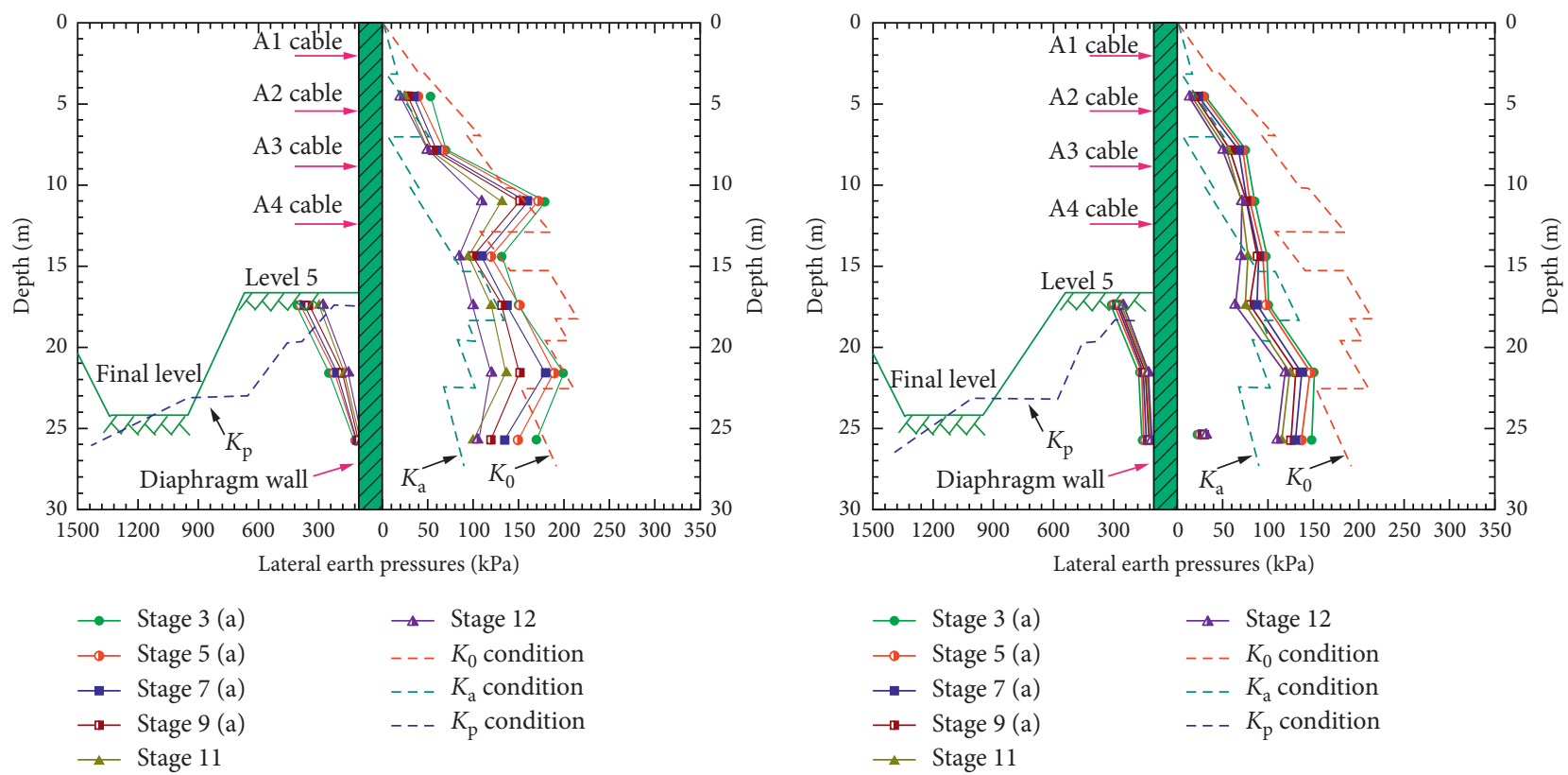

(d)

FIgURE 16: Distribution of the measured lateral earth pressures along depth at different construction stages. (a) The east segment. (b) The north segment. (c) The west segment. (d) The south segment.

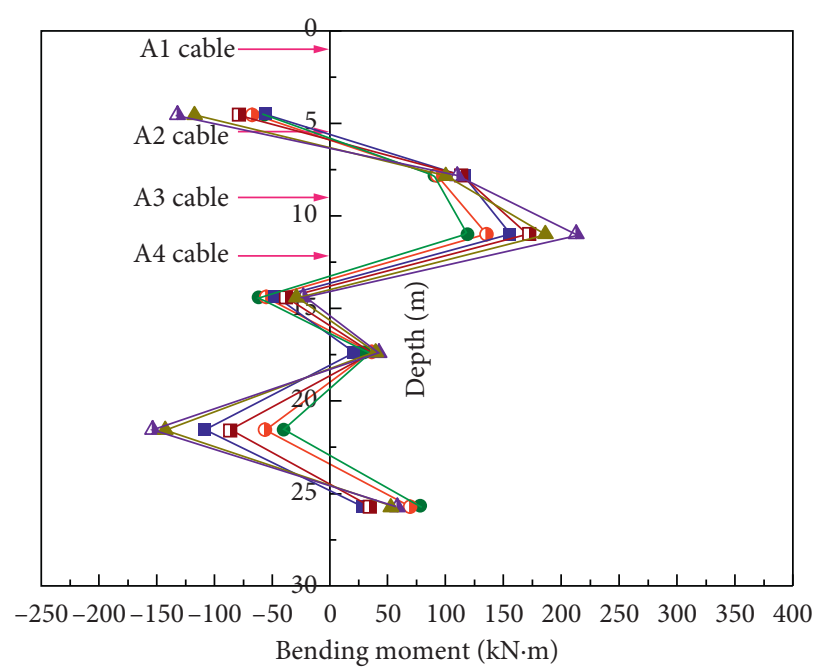

$\rightarrow$ Stage 3 (a)

- - Stage 5 (a)

$\rightarrow$ Stage 7 (a) (c)

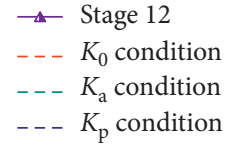

)
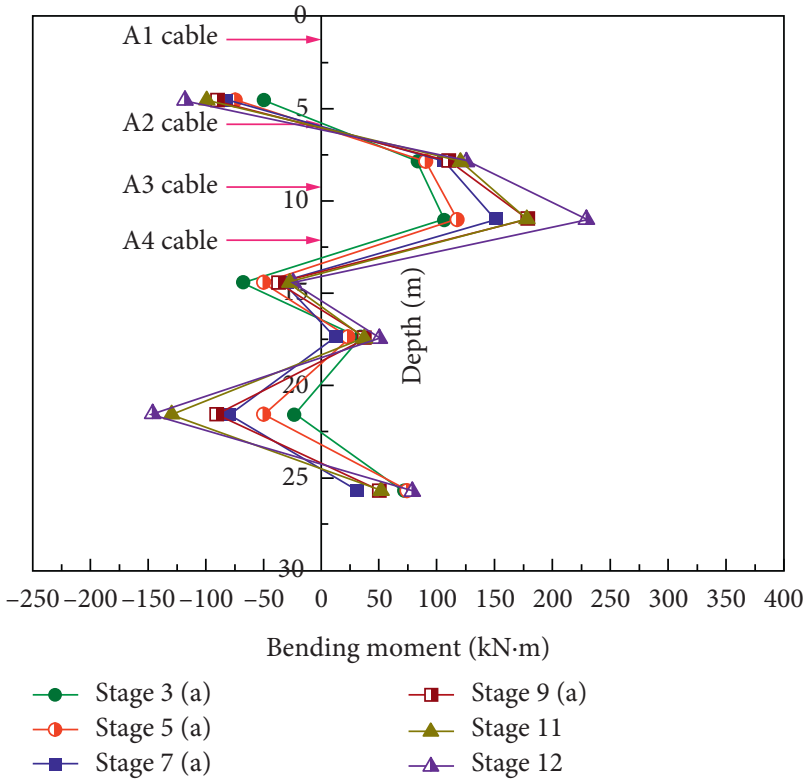

(b)

Figure 17: Continued. 

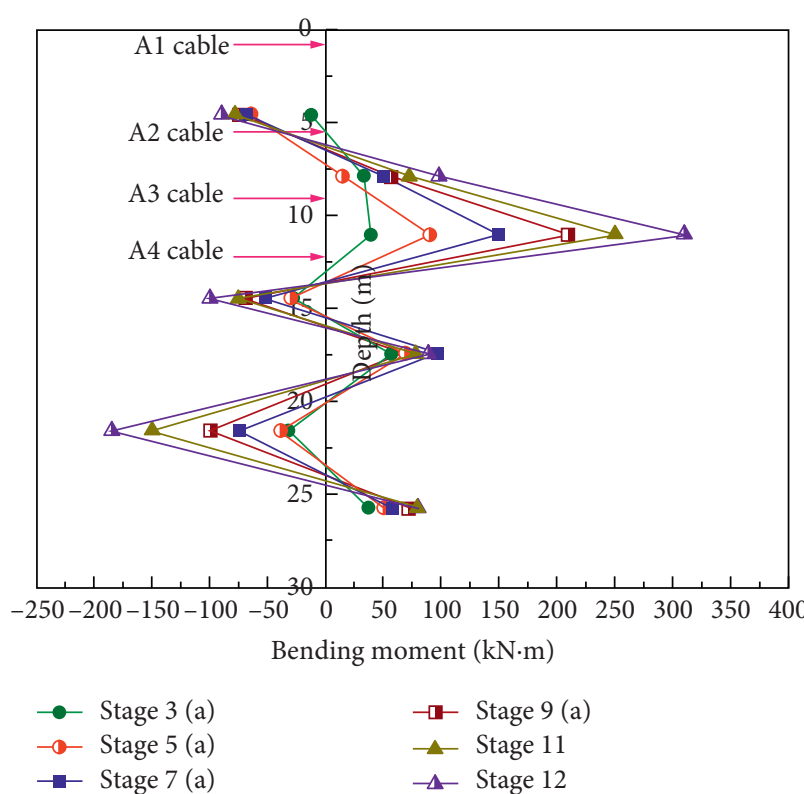

\section{-๘- Stage 9 (a)}

- Stage 11

$\boldsymbol{\Delta}$ Stage 12

(c)

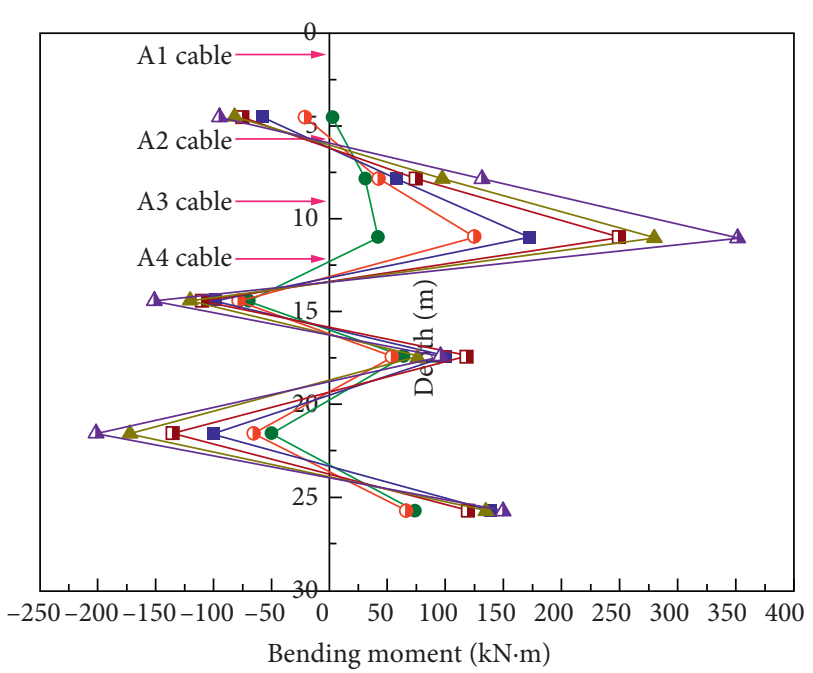

$\longrightarrow$ Stage 3 (a)
$-\bullet$ Stage 5 (a)
$\rightarrow-$ Stage 7 (a)

$-\square-$ Stage 9 (a)

$\_$Stage 11

-4 Stage 12

(d)

Figure 17: The bending moment of diaphragm wall. (a) The east segment. (b) The north segment. (c) The west segment. (d) The south segment.

Figure 16(a), the observed lateral passive pressure on the excavation side is substantially smaller than the theoretical $K_{\mathrm{p}}$ pressure. Their magnitudes decrease every stage and decay severely along the embedded depth, whereas the tendency of the lateral earth pressure line is different with some publications $[33,40]$. This occurrence would be attributed to the soil properties in this study. The deformation of diaphragm wall movements is rarely little and does not cause failure of the soil at the embedded depth, so that the magnitudes of the lateral passive pressure are small.

To verify the earth pressure envelope in Figure 16(a), the measured pressure data of the other three diaphragm walls from this study are shown in Figures 16(b)-16(d). According to Figures $16(\mathrm{~b})-16(\mathrm{~d})$, it is noticed that the initial readings also approach the $K_{\mathrm{o}}$ condition and the total lateral earth pressures in the unexcavated side are between the theoretical $K_{\mathrm{a}}$ pressure and theoretical $K_{\mathrm{o}}$ pressure. The maximum lateral active earth pressures of three diaphragm walls above the excavation bases range between $0.4 H_{\mathrm{e}}$ and $0.6 \mathrm{H}_{\mathrm{e}}$. The observed lateral passive pressures of three diaphragm walls are substantially smaller than the theoretical $K_{\mathrm{p}}$ pressure. The lateral passive earth pressures on the excavation side also decrease every stage and decay severely along the embedded depth on account of the soil properties in this study.

3.8. Internal Force Analysis of Diaphragm Wall. According to the field data, Figure 17 presents the wall bending moments at stages 3 (a), 5 (a), 7 (a), 9 (a), 11, and 12. The variation tendency of the bending moments is similar in every diaphragm wall. And it can be observed that the bending moments of diaphragm wall increase while the excavation goes deeper. The value of the bending moment is between $200 \mathrm{kN} \cdot \mathrm{m}$ and $350 \mathrm{kN} \cdot \mathrm{m}$. Compared with Figure 16, the maximum bending moments computed from the rebar strain gauges occur at the location where the maximum lateral soil pressure occurs. The bending moment profiles are scattering, and this will be mainly attributed to uneven curvature of wall deflection profiles. From the field data, the bending moment will become small when the cable is under construction at the corresponding depth, simultaneously. Such a phenomenon can probably be explained that the cable supplies the resistance torque for the diaphragm wall, so that the value of bending moment becomes small. However, the related data about this phenomenon are not placed in Figure 17 because of a large amount of data. This study is not investigated by numerical simulation, and the numerical simulation will be applied in the next step.

3.9. Axial Anchoring Forces. Four sets of anchor dynamometer were installed in the northern side, the southern side, the western side, and the eastern side of the excavation, respectively. The design axial loads of anchors in typical section are summarized in Table 2. The measured results of sixteen axial force gauges of anchor are presented in Figure 18. It is found that tension of anchors has two stages. In the first stage, the tension of anchors appears to increasing gradually. In the second stage, tension of anchors will tend to be stable during the excavation procedure. According to Figure 18, the axial anchoring forces of A1, A2, A3, and A4 increase gradually to $120.26 \mathrm{kN}, 253.29 \mathrm{kN}, 220.28 \mathrm{kN}$, and $118.5 \mathrm{kN}$, respectively. The axial anchoring forces of A5, A6, $\mathrm{A} 7$, and A8 increase gradually to $306.35 \mathrm{kN}, 136.64 \mathrm{kN}$, $212.2 \mathrm{kN}$, and $117.3 \mathrm{kN}$, respectively. The axial anchoring forces of A9, A10, A11, and A12 increase gradually to 
TABLE 2: The prestressed anchor design parameters.

\begin{tabular}{|c|c|c|c|c|c|c|c|}
\hline site & Support type & Anchor & Angle $\left({ }^{\circ}\right)$ & Diameter $(\mathrm{mm})$ & Free segment $(\mathrm{m})$ & Anchoring segment $(\mathrm{m})$ & Preload $(\mathrm{kN})$ \\
\hline \multirow{4}{*}{$\mathrm{H}-\mathrm{H}$ segment } & \multirow{4}{*}{ Diaphragm wall } & MG1 & 20 & 150 & 12.5 & 15.5 & 145 \\
\hline & & MG2 & 20 & 150 & 10.5 & 19.0 & 200 \\
\hline & & MG3 & 20 & 150 & 8.5 & 18.5 & 150 \\
\hline & & MG4 & 20 & 150 & 6.0 & 13.0 & 105 \\
\hline \multirow{4}{*}{ L-L segment } & \multirow{4}{*}{ Diaphragm wall } & MG1 & 25 & 150 & 12.5 & 15.0 & 200 \\
\hline & & MG2 & 22 & 150 & 10.5 & 19.5 & 280 \\
\hline & & MG3 & 20 & 150 & 8.5 & 19.5 & 240 \\
\hline & & MG4 & 20 & 150 & 6.0 & 14.5 & 185 \\
\hline
\end{tabular}

Note. MG1, the first row; MG2, the second row; MG3, the third row; MG4, the fourth row.

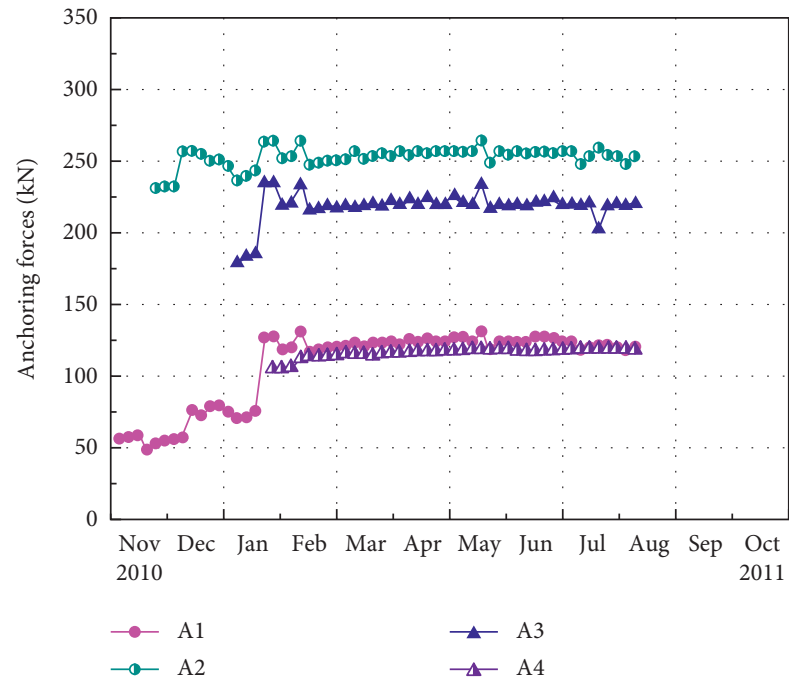

(a)

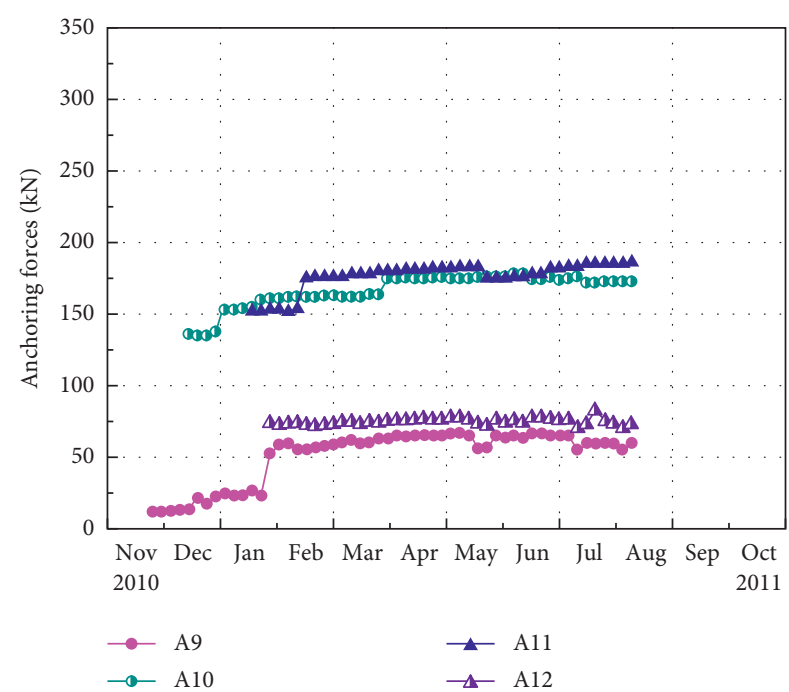

(c)

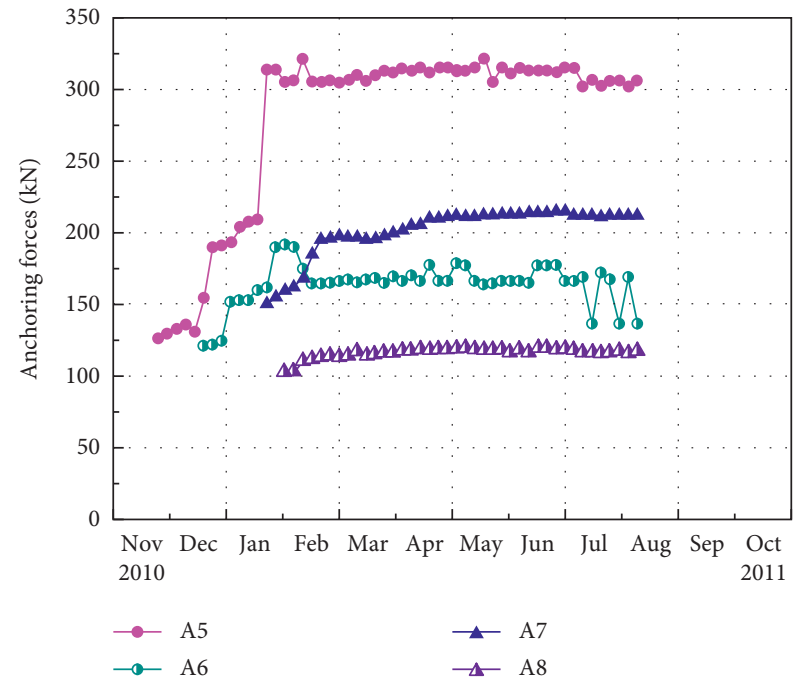

(b)

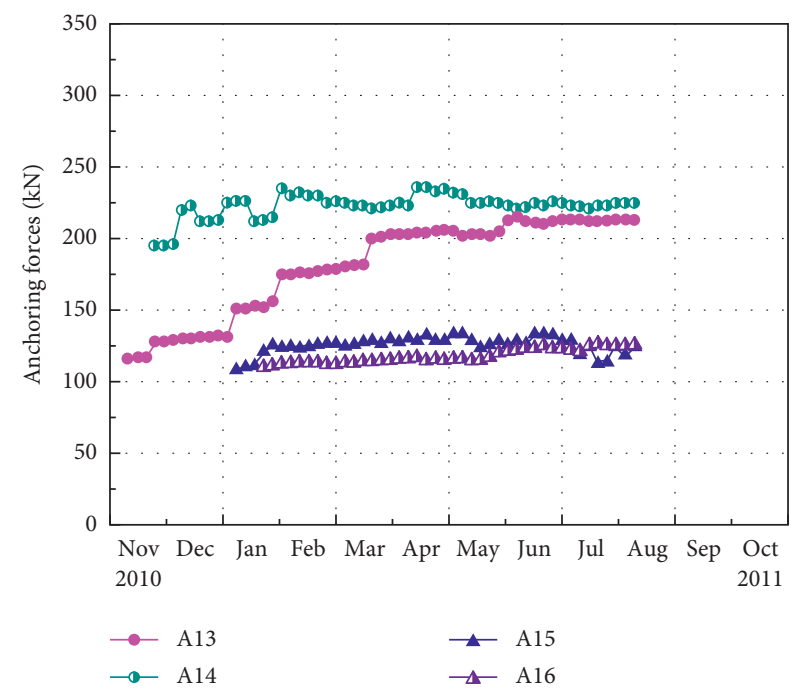

(d)

FIgURE 18: Axial anchoring forces during excavation. (a) The east segment. (b) The north segment. (c) The west segment. (d) The south segment.

$59.64 \mathrm{kN}, 173.5 \mathrm{kN}, 186.2 \mathrm{kN}$, and $73.34 \mathrm{kN}$, respectively. The axial anchoring forces of A13, A14, A15, and A16 increase gradually to $213.3 \mathrm{kN}, 225.8 \mathrm{kN}, 124.51 \mathrm{kN}$, and $125.3 \mathrm{kN}$, respectively. By further examination at anchors, it can be observed that the axial anchoring forces of the top three layers of anchors change significantly during the excavation. However, the axial anchoring forces of the fourth layer of anchors change little compared with the top three 


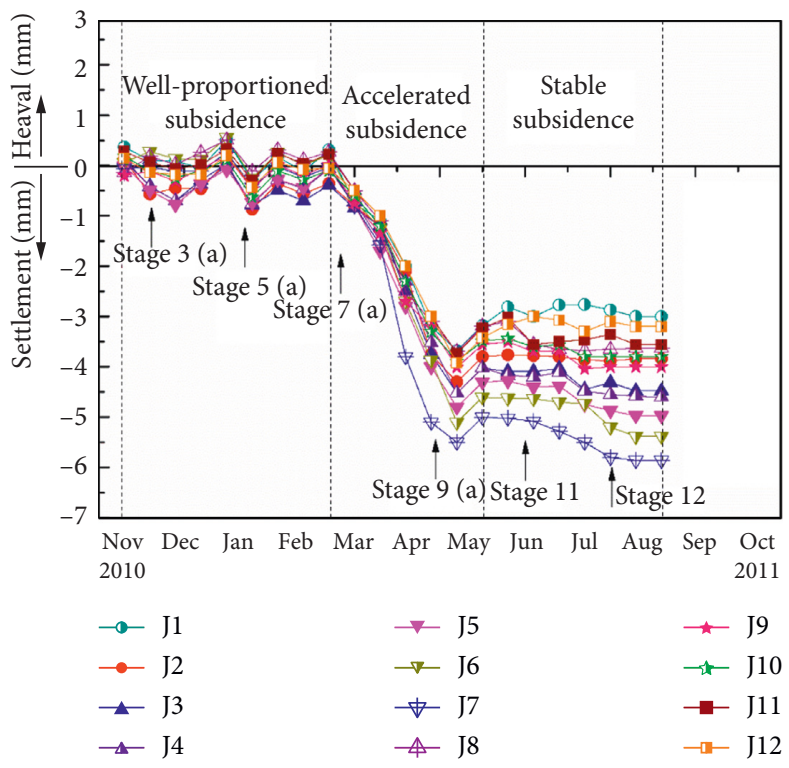

Figure 19: Settlement developments of adjacent Unicom building.

rows. Therefore, the top three layers of anchors should be paid attention to during the excavation procedure.

\subsection{Settlements of Adjacent Building. One Unicom building} is adjacent to excavation $8 \mathrm{~m}$ away. Figure 19 presents the layout of the building settlement monitoring points. From Figure 19, it is observed that the settlement of the Unicom building has three stages: a uniform subsidence stage, an accelerated subsidence stage, and a stable subsidence stage. J7 locates on the western side of building and J1 and J12 locate on the eastern side of building. The positive value $Y$ indicates upward displacement and the negative value $Y$ indicates downward displacement.

The excavation construction used dewatering wells for precipitation. A great amount of excavation external water flowed into excavation along cables hole when cables were under construction. Then, the pore-water pressure in soil dissipated, and settlements of the building were generated due to soil effective stress increasing. The soil surrounding building appeared empty state after excavation, and the soil generated shear failure with soil slipping forward to the excavation site. The ground further away from excavation was disturbed lightly. $\mathrm{J7}$ was adjacent to the pit edge $8 \mathrm{~m}$ away while the final settlement was $5.86 \mathrm{~mm}$. This settlement was the maximum in all subsidence monitoring points, which reflected that the sedimentation of $\mathrm{J} 7$ was the joint action by dewatering and excavation deformations. J1 and J12 were adjacent to pit edge $80 \mathrm{~m}$ away, and the final settlements were $3 \mathrm{~mm}$ and $3.2 \mathrm{~mm}$, respectively. The sedimentation of these two points was generated from dewatering primarily.

3.11. Pore-Water Pressures. As shown in Figure 20, there are four experiment diaphragm walls. Seven electronic-type piezometers were installed in the soil on the unexcavated side every diaphragm wall. Pore-water pressure acting on the wall could be obtained by observing the water pressure cells. As expected in Figure 20(a), all the pore pressures have reductions during cable construction in varying degrees. Such a phenomenon can probably be explained that a large amount of water flow into the excavation along the cable hole. Therefore, the pore-water pressure has substantial reductions during cable construction. By further examination, it is noticed that the pore pressures will not drop immediately in the beginning of the cable construction. The pore pressures will have some reductions after few days. This discrepancy should be attributed to the dissipation of the negative excess pore-water pressures. Figure 20(a) also shows that the pore pressures contour rise again after cable construction. This observation indicates that the variations of the lateral earth pressures and the deformation on the diaphragm walls will be attributed to the product of the reduction in the pore pressures at the corresponding depths. According to Ou et al. [40], the pore-water pressure changed only slightly in the zone bounded by the horizontal distance greater than $2 \mathrm{~m}$ from the wall. This achievement also explains why the maximum lateral wall deformation occurs near the excavation surface. The maximum reduction value of the pressures cell is 30 percent in the east segment. The pore pressure value will go up after the cable construction. As a consequence, the final pore pressure value decreases and the variation ranges between 10 percent and 30 percent throughout the whole project. To confirm the refined discussion from Figure 20(a), the measured pore pressures of the other three diaphragm walls from this study are presented in Figures 20(b)-20(d). As shown in Figures 20(b)-20(d), it is concluded that the pore pressures have a certain amount of reductions during cable construction and the pore pressures contour rise again after cable construction. It can be ascribed to the fact that that a large amount of water flows into the excavation along the cable hole. The variation range of the reductions is different throughout the whole project, when the three values are 20 


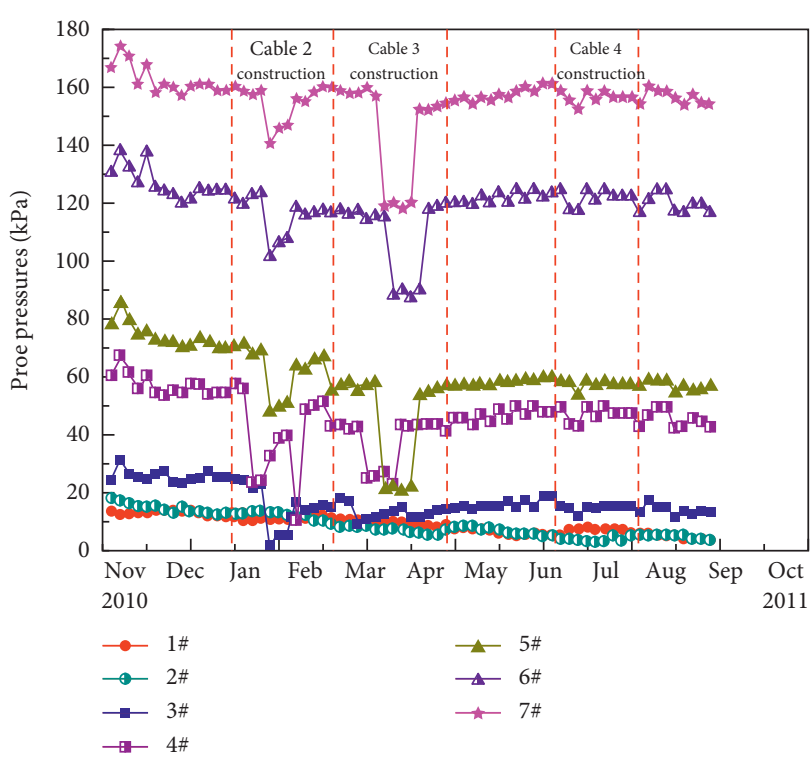

(a)

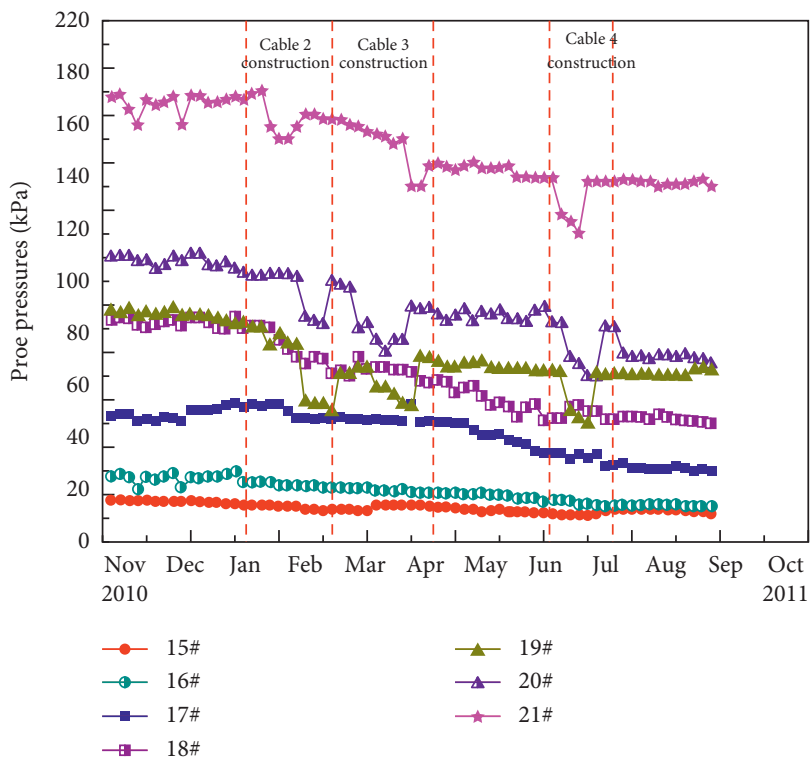

(c)

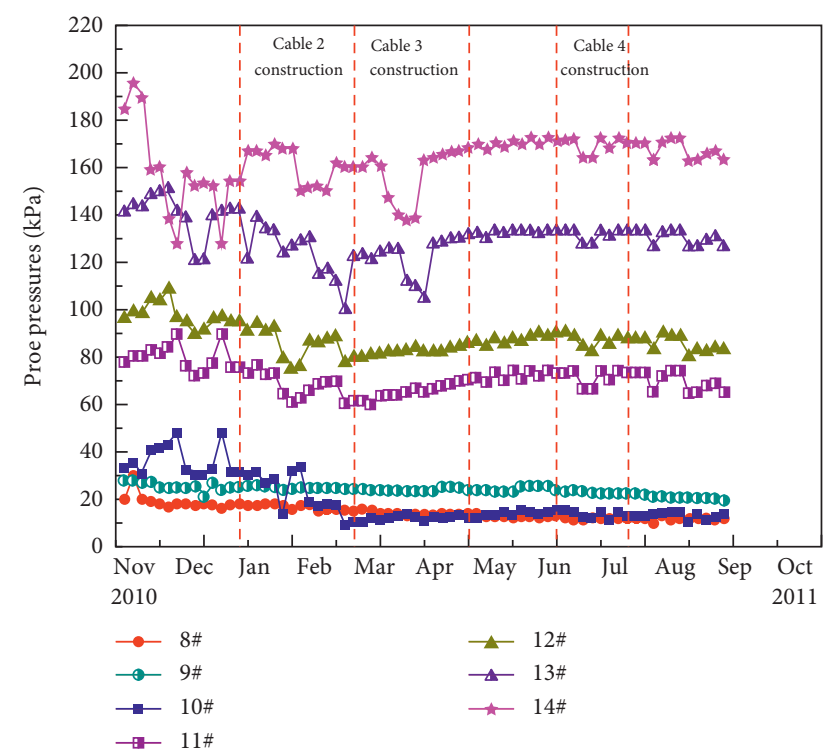

(b)

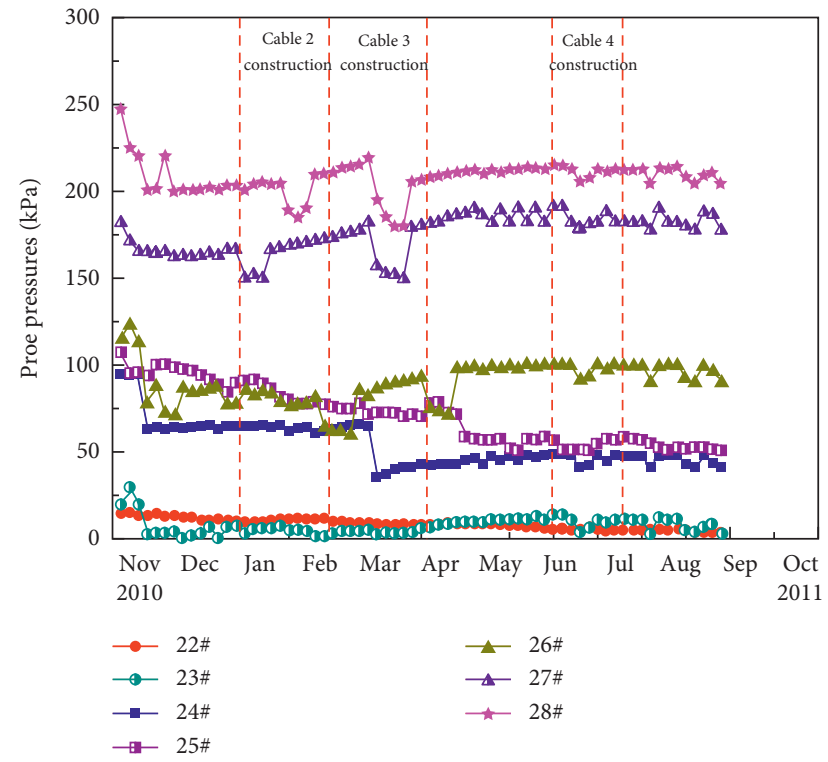

(d)

Figure 20: Variation of the pore pressures during construction. (a) The east segment. (b) The north segment. (c) The west segment. (d) The south segment.

percent $\sim 50$ percent, 15 percent $\sim 35$ percent, and 20 percent $\sim 37$ percent, respectively. Compared with Figures 10 and 16, the variations of the lateral earth pressures and the walls deformation will also be attributed to the product of the reduction in the pore pressures.

\section{Conclusions}

Based on the field measurements, the deformation characteristics of diaphragm walls-anchors retaining excavation case study is presented. The following conclusions may be drawn:
(1) The maximum deflection of the lateral wall is $0.07 \%$ $0.18 \%$ of the depth of excavation $\left(H_{\mathrm{e}}\right)$. The horizontal displacement of the capping beam increases linearly with time when the excavation reaches up to the final level.

(2) The ground surface settlement influence zone extends beyond $2.5 \mathrm{H}_{\mathrm{e}}$ from the pit for this project. The observed maximum ground settlement ranges from $0.67 \delta_{\mathrm{h}, \max }$ to $1.0 \delta_{\mathrm{h}, \max }$.

(3) The maximum lateral active earth pressures on the diaphragm walls above the excavation bases range between $0.4 H_{\mathrm{e}}$ and $0.6 \mathrm{H}_{\mathrm{e}}$. The value of the bending 
moment is between $200 \mathrm{kN} \cdot \mathrm{m}$ and $350 \mathrm{kN} \cdot \mathrm{m}$. The axial anchoring forces of the top three layers of anchors change significantly during the excavation while the axial anchoring force of the fourth layer of anchor be almost constant.

(4) The settlement of the adjacent building has three stages: a uniform subsidence stage, an accelerated subsidence stage, and a stable subsidence stage. The cable constructions limit the development of pipelines deformation and the pipeline settlements have rebounded and are stabilized eventually.

\section{Symbols}

$w: \quad$ Water content

$\gamma: \quad$ Unit weight of soil

$e: \quad$ Void ratio

$I_{\mathrm{P}}$ : $\quad$ Plastic index

$I_{\mathrm{L}}: \quad$ Liquid index

$k$ : $\quad$ Permeability of soil

$E_{\text {S1-2 }}$ : Constrained modulus

c: $\quad$ Cohesion intercept

$\varphi: \quad$ Friction angle

$a_{1-2}$ : Coefficient of compressibility

$N$ : $\quad$ Standard penetration test

$N_{63.5}$ : Heavy dynamic penetration test

$H_{\mathrm{e}}$ : $\quad$ Excavation depth $(\mathrm{m})$

$H_{\mathrm{w}}$ : Wall depth (m)

$d$ : Distance away from the diaphragm wall $(\mathrm{mm})$

$\delta_{\mathrm{v}}: \quad$ Ground surface settlement $(\mathrm{mm})$

$\delta_{\mathrm{v}, \max }:$ Maximum ground settlement $(\mathrm{mm})$

$\delta_{\mathrm{u}}: \quad$ Lateral displacement of soil $(\mathrm{mm})$

$\delta_{\mathrm{u}, \max }:$ Maximum lateral displacement of soil $(\mathrm{mm})$

$\delta_{\mathrm{h}, \mathrm{max}}:$ Maximum lateral wall deflection $(\mathrm{mm})$.

\section{Data Availability}

The data used to support the findings of this study are available from the corresponding author upon request.

\section{Conflicts of Interest}

The authors declare that they have no conflicts of interest.

\section{Acknowledgments}

This work was supported by the National Key R\&D Program of China (2016YFC0800200).

\section{References}

[1] R. Chen, F. Meng, Z. Li, Y. Ye, and J. Ye, "Investigation of response of metro tunnels due to adjacent large excavation and protective measures in soft soils," Tunnelling and Underground Space Technology, vol. 58, pp. 224-235, 2016.

[2] J. Han and D. Leshchinsky, "Analysis of back-to-back mechanically stabilized earth walls," Geotextiles and Geomembranes, vol. 28, no. 3, pp. 262-267, 2010.
[3] P.-G. Hsieh and C.-Y. Ou, "Shape of ground surface settlement profiles caused by excavation," Canadian Geotechnical Journal, vol. 35, no. 6, pp. 1004-1017, 1998.

[4] G. H. Lei, C. W. W. Ng, and D. B. Rigby, "Stress and displacement around an elastic artificial rectangular hole," Journal of Engineering Mechanics, vol. 127, no. 9, pp. 880-890, 2001.

[5] G. H. Lei, Y. B. Ai, and J. Y. Shi, "The interpretation of pendulum-type inclinometer readings," Canadian Geotechnical Journal, vol. 43, no. 2, pp. 210-216, 2006.

[6] E. H. Y. Leung and C. W. W. Ng, "Wall and ground movements associated with deep excavations supported by cast in situ wall in mixed ground conditions," Journal of Geotechnical and Geoenvironmental Engineering, vol. 133, no. 2, pp. 129-143, 2007.

[7] G. B. Liu, R. J. Jiang, C. W. W. Ng, and Y. Hong, "Deformation characteristics of a $38 \mathrm{~m}$ deep excavation in soft clay," $\mathrm{Ca}$ nadian Geotechnical Journal, vol. 48, no. 12, pp. 1817-1828, 2011.

[8] C. W. W. Ng, J. Shi, D. Mašín, H. Sun, and G. H. Lei, "Influence of sand density and retaining wall stiffness on threedimensional responses of tunnel to basement excavation," Canadian Geotechnical Journal, vol. 52, no. 11, pp. 1811-1829, 2015.

[9] C.-Y. Ou, P.-G. Hsieh, and Y.-L. Lin, "A parametric study of wall deflections in deep excavations with the installation of cross walls," Computers and Geotechnics, vol. 50, pp. 55-65, 2013.

[10] R. B. Peck, "Deep excavation and tunneling in soft ground. State-of the-art-report," in Proceedings of the 7th International Conference of Soil Mechanics and Foundation Engineering, pp. 225-281, International Society of Soil Mechanics and Geotechnical Engineering (ISSMGE), Mexico City, Mexico, August 1969.

[11] Y. Tan and D. Wang, "Characteristics of a large-scale deep foundation pit excavated by the central-island technique in Shanghai soft clay. I: bottom-up construction of the central cylindrical shaft," Journal of Geotechnical and Geoenvironmental Engineering, vol. 139, no. 11, pp. 1875-1893, 2013.

[12] J. H. Xiao and Y. B. Guan, "Resilient behavior of compacted silt under the repeated triaxial test," in Proceedings of the 10th International Conference of Chinese Transportation, Professionals North American Chinese Overseas Transportation AssociationBeijing University of Technology American Society of Civil EngineersTransportation Research BoardNational Natural Science Foundation of China, Beijing, China, August 2010.

[13] J. H. Xiao, C. H. Juang, K. Wei, and S. Q. Xu, "Effects of principal stress rotation on the cumulative deformation of normally consolidated soft clay under subway traffic loading," Journal of Geotechnical and Geoenvironmental Engineering, vol. 140, no. 4, Article ID 04013046, 2013.

[14] X. Xu, Q. Huang, Y. Ren, D. Y. Zhao, and J. Yang, "Sensor fault diagnosis for bridge monitoring system using similarity of symmetric responses," Smart Structures and Systems, vol. 23, no. 3, pp. 279-293, 2019.

[15] D. M. Zhang, Z. K. Huang, Z. Y. Yin, L. Z. Ran, and H. W. Huang, "Predicting the grouting effect on leakageinduced tunnels and ground response in saturated soils," Tunnelling and Underground Space Technology, vol. 65, pp. 76-90, 2017.

[16] D.-W. Zhang, J.-C. Shu, and J.-P. Sun, “Observed deformation characteristics of a deep excavation for the spring area in 
Jinan, China," Journal of Mountain Science, vol. 14, no. 3, pp. 581-594, 2017.

[17] G. Zheng, F. J. Wang, Y. M. Du, Y. Diao, Y. W. Lei, and X. S. Cheng, "The efficiency of the ability of isolation piles to control the deformation of tunnels adjacent to excavations," International Journal of Civil Engineering, vol. 16, no. 10, pp. 1475-1490, 2018.

[18] H. F. Zou, S. Y. Liu, G. J. Cai, and J. P. Anand, "Probabilistic identification of contaminated soils using resistivity piezocone penetration tests," Acta Geotechnica, vol. 75, no. 9, pp. 1-19, 2018.

[19] D. T. Goldberg, W. E. Jaworski, and M. D. Gordon, Lateral Support Systems and Underpinning: Construction Methods, Federal Highway Administration, Offices of Research \& Development, Washington, D.C, USA, 1976.

[20] P.-G. Hsieh and C.-Y. Ou, "Simplified approach to estimate the maximum wall deflection for deep excavations with cross walls in clay under the undrained condition," Acta Geotechnica, vol. 11, no. 1, pp. 177-189, 2016.

[21] Y. M. A. Hashash, A. Osouli, and C. Marulanda, "Central artery/tunnel project excavation induced ground deformations," Journal of Geotechnical and Geoenvironmental Engineering, vol. 134, no. 9, pp. 1399-1406, 2008.

[22] G. T. Kung, C. H. Juang, E. C. Hsiao, and Y. M. Hashash, "Simplified model for wall deflection and ground-surface settlement caused by braced excavation in clays," Journal of Geotechnical and Geoenvironmental Engineering, vol. 133, no. 6, pp. 731-747, 2007.

[23] H. J. Li, S. Y. Liu, and L. Y. Tong, "Evaluation of lateral response of single piles to adjacent excavation using data from cone penetration tests," Canadian Geotechnical Journal, vol. 56, no. 2, pp. 236-248, 2018.

[24] Y. Liu, L. Y. Tong, J. G. Lou, J. Lu, and J. Cao, "Sampled-data control for the synchronization of boolean control networks," IEEE Transactions on Cybernetics, vol. 49, no. 2, pp. 726-732, 2018.

[25] C. Moormann, "Analysis of wall and ground movements due to deep excavations in soft soil based on a new worldwide database," Soils and Foundations, vol. 44, no. 1, pp. 87-98, 2004.

[26] S. Mohammad, S. Pakbaz, K. H. Imanzadeh, and Bagherinia, "Characteristics of diaphragm wall lateral deformations and ground surface settlements: case study in Iran-Ahwaz metro," Tunnelling and Underground Space Technology, vol. 35, pp. 109-121, 2013.

[27] P. Ni, L. Song, G. Mei, and Y. Zhao, "Predicting excavationinduced settlement for embedded footing: case study," International Journal of Geomechanics, vol. 18, no. 4, Article ID 05018001, 2018.

[28] C. W. W. Ng and G. H. Lei, "An explicit analytical solution for calculating horizontal stress changes and displacements around an excavated diaphragm wall panel," Canadian Geotechnical Journal, vol. 40, no. 4, pp. 780-792, 2003.

[29] T. D. O'Rourke, "Ground movements caused by braced excavations," Journal of Geotechnical and Geoenvironmental Engineering, vol. 107, no. 9, pp. 1159-1178, 1981.

[30] Y. Tan and D. Wang, "Characteristics of a large-scale deep foundation pit excavated by the central-island technique in Shanghai soft clay. II: top-down construction of the peripheral rectangular pit," Journal of Geotechnical and Geoenvironmental Engineering, vol. 139, no. 11, pp. 1894-1910, 2013.

[31] Y. Tan and D. L. Wang, "Structural behaviors of large underground earth-retaining systems in Shanghai. I: unpropped circular diaphragm wall," Journal of Performance of Constructed Facilities, vol. 29, no. 2, Article ID 04014058, 2015.

[32] Y. Tan and D. L. Wang, "Structural behaviors of large underground earth-retaining systems in Shanghai. II: multipropped rectangular diaphragm wall," Journal of Performance of Constructed Facilities, vol. 29, no. 2, Article ID 04014059, 2013.

[33] Y. Tan, B. Wei, X. Zhou, and Y. Diao, "Lessons learned from construction of Shanghai metro stations: importance of quick excavation, prompt propping, timely casting, and segmented construction," Journal of Performance of Constructed Facilities, vol. 29, no. 4, Article ID 04014096, 2014.

[34] J. H. Wang, Z. H. Xu, and W. D. Wang, "Wall and ground movements due to deep excavations in Shanghai soft soils," Journal of Geotechnical and Geoenvironmental Engineering, vol. 136, no. 7, pp. 985-994, 2010.

[35] A. J. Whittle, G. Corral, L. C. Jen, and R. P. Rawnsley, "Prediction and performance of deep excavations for courthouse station, Boston," Journal of Geotechnical and Geoenvironmental Engineering, vol. 141, no. 4, pp. 1246-1259, 2015.

[36] M. Zhang and L.-Y. Tong, "Determination of hydraulic conductivity using a modified cylindrical-half-spherical piezocone model," International Journal of Civil Engineering, vol. 17, no. 2, pp. 161-170, 2019.

[37] G. Zheng, X. S. Cheng, Y. Diao, and H. X. Wang, "Concept and design methodology of redundancy in braced excavation and case histories," Geotechnical Engineering Journal of the SEAGS \& AGSSEA, vol. 42, no. 3, pp. 13-21, 2011.

[38] G. Zheng, C.-F. Zeng, Y. Diao, and X.-L. Xue, "Test and numerical research on wall deflections induced by pre-excavation dewatering," Computers and Geotechnics, vol. 62, pp. 244-256, 2014

[39] M. Long, "Database for retaining wall and ground movements due to deep excavations," Journal of Geotechnical and Geoenvironmental Engineering, vol. 127, no. 3, pp. 203-224, 2001.

[40] C.-Y. Ou, P.-G. Hsieh, and D.-C. Chiou, "Characteristics of ground surface settlement during excavation," Canadian Geotechnical Journal, vol. 30, no. 5, pp. 758-767, 1993.

[41] A. J. Whittle, "Evaluation of a constitutive model for overconsolidated clays," Géotechnique, vol. 43, no. 2, pp. 289-313, 1993.

[42] L. Bjerrum and O. Eide, "Stability of strutted excavations in clay," Géotechnique, vol. 6, no. 1, pp. 32-47, 1956.

[43] R. J. Finno, J. Benoit, and C. K. Chung, "Field and laboratory measured values of $\mathrm{K}_{\mathrm{o}}$ in Chicago clays," in Proceedings of the 3rd International Symposium on Presuremeters, pp. 171-186, Oxford University, London, UK, 1990.

[44] A. I. Mana and G. W. Clough, "Prediction of movements for braced cuts in clay," Journal of Geotechnical and Geoenvironmental Engineering, vol. 107, no. 6, pp. 759-777, 1981.

[45] J. C. Wallace, C. E. Ho, and M. M. Long, "Retaining wall behaviour for a deep basement in Singapore marine clay," in Proceedings of the International Conference on Retaining Structures, pp. 195-204, Thomas Telford Ltd., Cambridge, UK, July 1992.

[46] G. W. Clough and T. D. O’Rourke, "Construction induced movements of in-situ walls," in Design and Performance of Earth Retaining Structures, pp. 439-470, ASCE, Reston, VA, USA, 1990. 


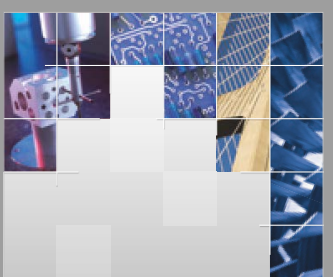

\section{Enfincering}
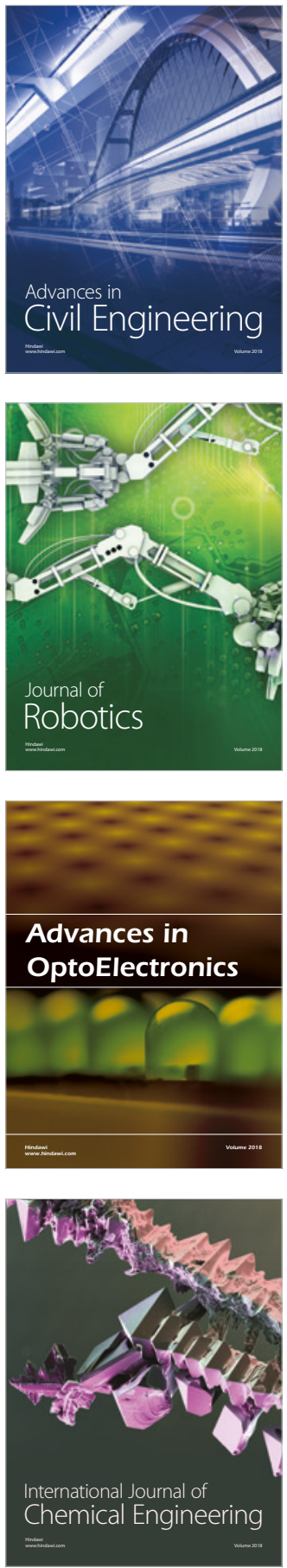

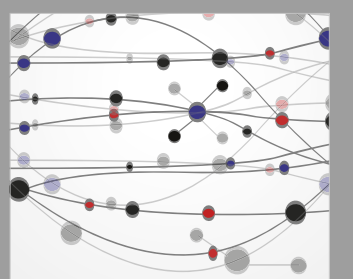

\section{Rotating \\ Machinery}

The Scientific World Journal

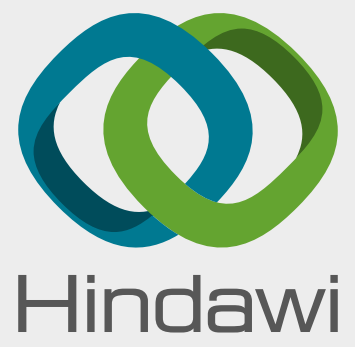

Submit your manuscripts at

www.hindawi.com
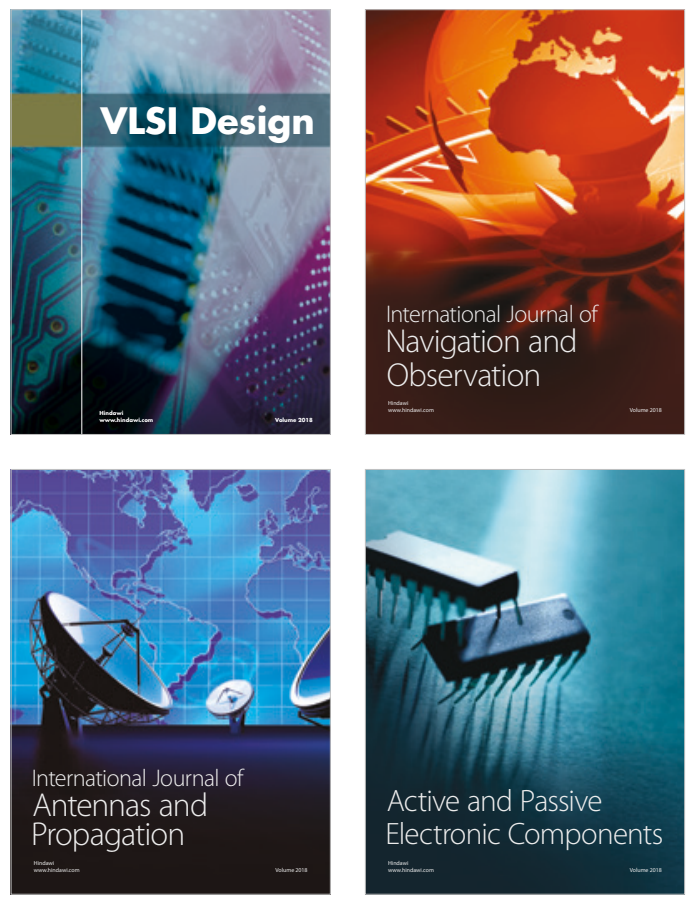
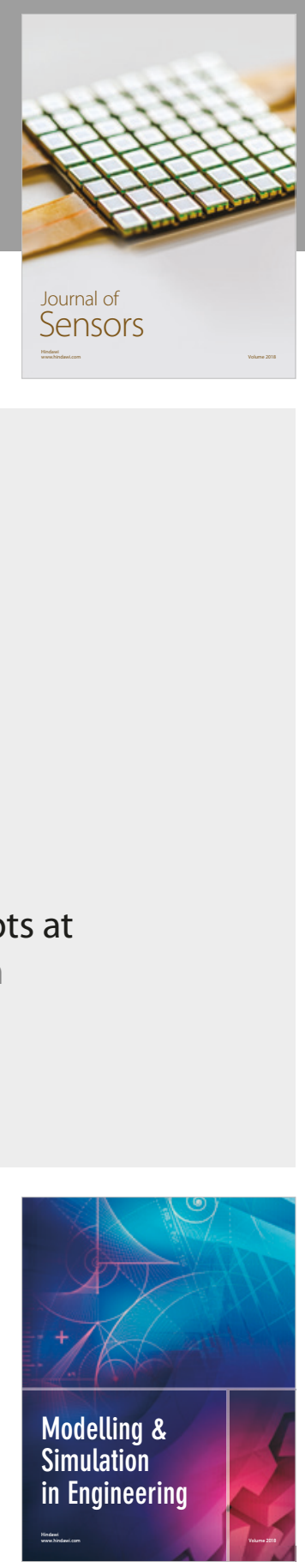

\section{Advances \\ Multimedia}
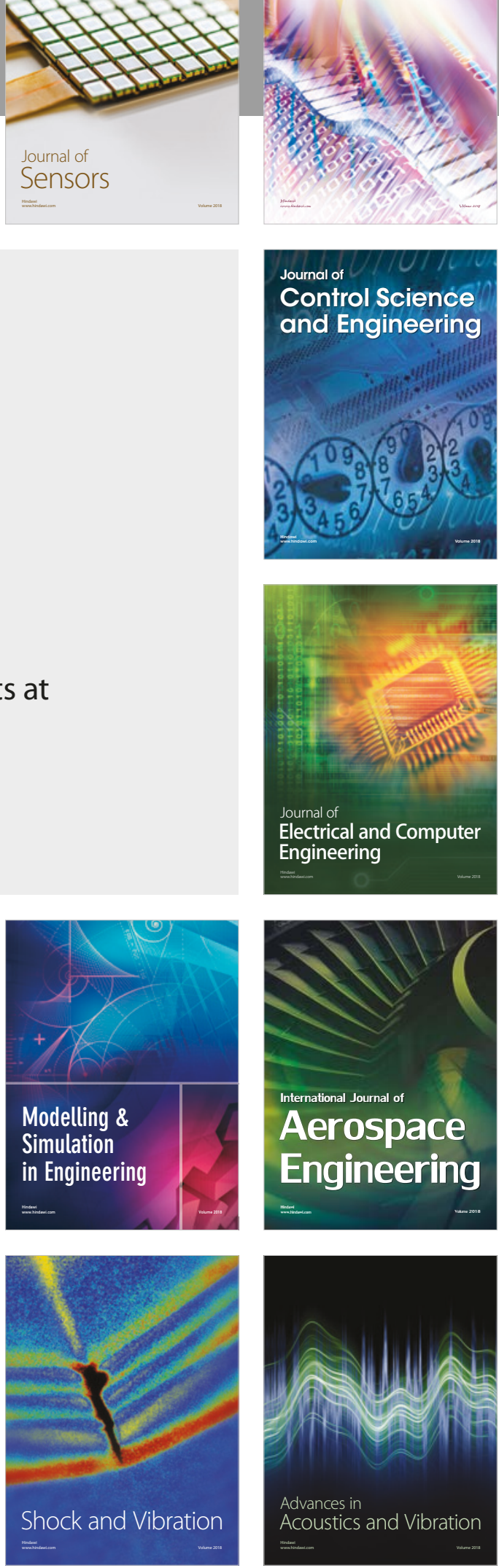